\title{
Alzheimer's Disease, Cerebrovascular Disease, and the $\beta$-amyloid Cascade
}

\author{
Kie Honjo, Sandra E. Black, Nicolaas P.L.G. Verhoeff
}

\begin{abstract}
Alzheimer's disease (AD), considered the commonest neurodegenerative cause of dementia, is associated with hallmark pathologies including extracellular amyloid- $\beta$ protein $(A \beta)$ deposition in extracellular senile plaques and vessels, and intraneuronal tau deposition as neurofibrillary tangles. Although AD is usually categorized as neurodegeneration distinct from cerebrovascular disease (CVD), studies have shown strong links between AD and CVD. There is evidence that vascular risk factors and CVD may accelerate A $\beta$ 40-42 production/ aggregation/deposition and contribute to the pathology and symptomatology of AD. A $\beta$ deposited along vessels also causes cerebral amyloid angiopathy. Amyloid imaging allows in vivo detection of AD pathology, opening the way for prevention and early treatment, if disease-modifying therapies in the pipeline show safety and efficacy. In this review, we review the role of vascular factors and $\mathrm{A} \beta$, underlining that vascular risk factor management may be important for $\mathrm{AD}$ prevention and treatment.
\end{abstract}

RÉSUMÉ: Maladie d'Alzheimer, maladie cérébrovasculaire et cascade $\boldsymbol{\beta}$-amyloïde. La maladie d'Alzheimer (MA), considérée comme la cause neurodégénérative de démence la plus fréquente, est associée à des pathologies caractéristiques dont le dépôt extracellulaire de protéine $\beta$-amyloïde (A $\beta$ ) dans les plaques séniles extracellulaires et les vaisseaux et le dépôt intraneuronal de la protéine tau sous forme d'amas neurofibrillaires. Bien que la MA soit habituellement classifiée comme une neurodégénérescence distincte de la maladie cérébrovasculaire (MCV), des études ont montré des liens étroits entre la MA et la MCV. Il existe des données selon lesquelles les facteurs de risque vasculaire et la MCV peuvent accélérer la production/l'agrégation/le dépôt de l'A $\beta$ 40-42 et contribuer à la pathologie et à la symptomatologie de la MA. Le dépôt de l'A $\beta$ le long des vaisseaux cause également l'angiopathie amyloïde cérébrale. L'imagerie de l'amyloïde permet la détection in vivo de la pathologie de la MA, ouvrant ainsi la voie à la prévention et au traitement précoces, si des traitements modificateurs de la maladie actuellement en développement s'avèrent sûrs et efficaces. Nous revoyons ici le rôle des facteurs de risque vasculaire et de l'A $\beta$, tout en soulignant que le contrôle des facteurs de risque vasculaire peut être important dans la prévention et le traitement de la MA.

Can J Neurol Sci. 2012; 39: 712-728

Alzheimer's disease (AD) is one of the most important disorders causing dementia in the elderly, with an estimated 36 million people affected worldwide in 2010 . The AD population is expected to rise to 66 million by 2030 , and 115 million by $2050 .{ }^{1}$ Over 500,000 Canadians have dementia now, and over 100,000 develop some form of dementia each year. This exceeds the 40,000-50,000 new cases of stroke that occur in Canada each year. Estimates are, that by 2038, the annual incidence of new dementia cases per year in Canada will be 257,800 , which is over double the current rate, and the prevalence will be $1,125,200$ by $2038 .^{2}$ In the USA, currently 5.3 million people have dementia, ${ }^{3}$ but this is expected to increase to 13.2 million by $2050 .{ }^{4}$ Currently, AD pathology contributes significantly approximately 60 per cent (50-75\% range) of the total number of people with dementia living in developed countries. Moreover, in the USA, AD is the third most costly disease following cardiovascular disease and depression. ${ }^{5}$ Despite the large effort to understand the cause of this disease, its pathogenesis has still to be fully elucidated.

The first case of AD reported by Dr. Alois Alzheimer in 1906 revealed not only the presence of senile plaques and neurofibrillary tangles (NFT), but also the presence of cerebrovascular disease (CVD). Despite this seminal observation of concomitant CVD and the hallmark pathologies of $\mathrm{AD}$ in this important index case, Alzheimer himself and subsequent experts emphasized that plaques and tangles occurred in a presenile neurodegenerative disease distinct from CVD. ${ }^{6}$ Although the cognitive profile, mode of onset, and progression often differ in $\mathrm{AD}$ and vascular dementia (VaD), many studies have shown strong links between the two pathologies. A number of studies have shown that the risk factors for CVD are quite similar to those for non-genetic $\mathrm{AD}^{7,8}$, and that symptoms of dementia are more readily expressed when Alzheimer's brain pathology coexists with cerebrovascular lesions. ${ }^{9-12}$ It has been also shown that cerebral infarction and other types of brain injury can accelarate Alzheimer neuropathology. ${ }^{13-15}$ Furthermore, amyloid- $\beta$ protein $(A \beta)$

\footnotetext{
From the L.C. Campbell Cognitive Neurology Research Unit; Heart and Stroke Foundation Centre for Stroke Recovery; Brain Science Research Program, Sunnybrook Research Institute; Department of Medicine (Neurology), Sunnybrook Health Sciences Centre \& University of Toronto: Rotman Research Institute (KH, SEB); KuninLunenfeld Applied Research Unit, Baycrest, Department of Psychiatry (NPLGV), University of Toronto, Toronto, Ontario, Canada; Department of Neurology (KH), Hiroshima University Hospital, Hiroshima, Japan.

Received October 28, 2011. Final Revisions Submitted June 30, 2012 Correspondence to: Kie Honjo, 1-2-3 Kasumi, Minami-ku, Hiroshima, Hiroshima, Japan 734-8551. Email: kiehon@hotmail.com.
} 
deposition in the brain occurs not only in the parenchyma but also in the vessel walls, causing cerebral amyloid angiopathy (CAA).

It has been increasingly accepted that $\mathrm{AD}$ is linked to $\mathrm{A} \beta$ accumulation and NFT formation, which begins at a very early stage of disease progression in the brain of AD patients, often decades before clinical symptoms begin, and also that $A \beta$ deposition can be present even though clinical dementia is not manifest. ${ }^{12,16}$ Hence, it has been thought that $\mathrm{A} \beta$ accumulation might be one of the earliest changes in the normal aging human brain. Recent basic research, however, provides evidence that $A \beta$ in oligomeric form is neurotoxic, even when it has not fibrillated and deposited as plaques in the brain. ${ }^{17-19}$ As $A \beta$ deposition is known to occur in the preclinical stage of $\mathrm{AD}$, preclinical detection in vivo of $\mathrm{AD}$ is an important goal if amyloid-reducing drugs become available.

Recently, diagnostic criteria for Alzheimer's disease have been updated and include $\mathrm{A} \beta$ imaging. ${ }^{20}$ Much effort has been made to develop sensitive and specific neuroimaging techniques to assist in the diagnosis of $\mathrm{AD}$, but so far, no definitive criteria have been determined for diagnosing $\mathrm{AD}$ using conventional imaging modalities. ${ }^{21}$ Since AD has specific pathological characteristics in the postmortem brain, current imaging efforts are focused on direct imaging of the pathological process, especially of $\mathrm{A} \beta$, in vivo. Positron emission tomography (PET) to detect $A \beta$ deposition in the brain has been applied to normal elderly, prodromal AD as well as AD dementia populations..$^{22-26}$

These developments warrant a reconsideration of relationships among $\mathrm{AD}, \mathrm{CVD}$, and $\mathrm{A} \beta$, especially since imaging methods may soon allow detection of amyloid as well as vascular brain injury in vivo. In particular, there is growing evidence that non-genetic AD may be initiated by vascular factors that precede and may foment the neurodegenerative cascade. ${ }^{27}$ We review some of the recently published basic and clinicopathological research data that support this hypothesis. We also review the pathogenesis of $\mathrm{A} \beta$, and the opportunity that $\mathrm{A} \beta$ imaging offers for detecting preclinical AD. Our purpose is to give the neurological community an overview of basic and clinical research studies related to $\mathrm{A} \beta$ and $\mathrm{AD}$, and to discuss vascular risk factors and the pathogenesis of $\mathrm{AD}$ with a special reference to the role of CVD in the emergence of $\mathrm{AD}$ dementia. Clinical implications of $\mathrm{A} \beta$ imaging for early detection of $\mathrm{AD}$ are also discussed.

\section{DEFINITION}

Dementia has been generally defined as acquired persistent impairments in two or more cognitive domains (one of which should be memory for typical AD), sufficient to cause decline in ability to carry out social or occupational functioning independently. The most prevalent types of dementia are classified by presumed etiology into $\mathrm{VaD}$ caused by vascular lesions and $\mathrm{AD}$ resulting from a neurodegenerative process. According to the Diagnostic and Statistical Manual of Mental Disorders, Fourth Edition, Text Revision (DSM-IV-TR) ${ }^{28}$ and the previously widely used criteria formulated and recently revised by the National Institute of Neurological and Communicative Disorders and Stroke-Alzheimer's Disease and Related Disorder Association (NINDs-ADRDA), which have just recently been revised in $2011^{20}$, a demented individual who has evidence of substantial CVD previously is excluded from the diagnosis of probable AD. By DSM-IV-TR, this person would be automatically classified as $\mathrm{VaD}$ instead. Other research criteria specify imaging and clinical criteria including mode of onset and progression for $\mathrm{VaD} .{ }^{29}$ However, CVD (for example, lacunar infarcts, CAA, microbleeds, and white matter changes) is frequently found in the brains of $\mathrm{AD}$ patients. ${ }^{30}$ The recent revision of the NINDs-ADRDA acknowledge that CVD is common and if concommitant CVD is evident, the designation of possible AD can be used..$^{20}$

Some researchers have hypothesized that there are two major pathological pathways leading to development of $\mathrm{AD}$ : the amyloid cascade or vascular injury. The first step of the amyloid hypothesis is excessive miscleavage of amyloid precursor protein (APP) into longer fragments $A \beta$ 40-42, which are neurotoxic and prone to fibrillate and deposit in senile plaques or along vessels, eventually leading to AD dementia. ${ }^{31}$ On the other hand, the vascular hypothesis suggests that ischemic changes and hypoperfusion associated with aging and vascular risk factors, disturbing blood supply and metabolism, lead to neuronal and/or neuroglial energy failure which not only causes injury, but also accelerates amyloid over-production and reduces clearance, ${ }^{32}$ eventually leading to $\mathrm{AD}$ pathology. ${ }^{33} \mathrm{We}$ will consider the evidence that has been put forward to support the pathogenic role of vascular injury in AD.

\section{EPIDEMIOLOGY}

Numerous prospective and retrospective population-based epidemiological studies have revealed a number of risk factors associated with both $\mathrm{AD}$ and CVD. These include cerebrovascular and cardiovascular risk factors, such as hypercholesterolemia, hypertension, hyperhomocysteinemia, atherosclerosis, diabetes mellitus, coronary artery disease, atrial fibrillation, high fibrinogen levels, high serum viscosity, smoking, and obesity. ${ }^{7,8}$ Ischemic stroke and transient ischemic attacks are also considered to be risk factors for AD. ${ }^{7,9}$ Related to those factors, age is also clearly one of the most important risk factors for $\mathrm{AD}$. The incidence of $\mathrm{AD}$ is strongly and positively correlated with age, from less than $1 \%$ in people aged 65 years to over $25 \%$ in those who are aged 85 years or over in the Canadian Longitudinal Study on Aging. ${ }^{34,35}$ One meta-analysis revealed that prevalence of $\mathrm{AD}$ consistently doubles every 5.1 years after age 60 , confirming the strong relationship between prevalence of $\mathrm{AD}$ and age. ${ }^{36}$

Other predisposing factors include alcoholism, traumatic brain injury (TBI), aluminium toxicity, and herpes simplex virus infection, which are believed to cause inflammation and free radical damage to neuronal and other cells and subsequent gliosis. Significant TBI is also associated with overproduction of $\mathrm{A} \beta$ in the acute phase. Genetic polymorphism for apolipoprotein E type 4 (APOE- $\varepsilon 4$ ) is the strongest genetic susceptibility risk factor for late-onset AD so far recognized, though recent studies have identified weaker genetic factors such as polymorphisms in the SORL1 gene for late onset $\mathrm{AD},{ }^{37}$ as well as several other gene loci. ${ }^{38}$ Since the APOE- $\varepsilon 4$ allele has been reported to be a risk factor causing various cerebrovascular and cardiovascular events $^{8,39}$, it is of great importance to better understand the role of this gene in the pathogenesis of AD in association with CVD. There are also gene mutations (e.g., PS1 on chromosome 14, 
PS2 on chromosome 1, and APP on chromosome 21) for familial forms of early onset $\mathrm{AD}^{40}$ and for autosomal dominant CAA. ${ }^{41}$

\section{EVIDENCE OF RISK FACTORS FOR AD AND CVD (Figure 1)}

\section{a) Risk factors}

\section{Aging}

Aging is one of the most important factors causing various types of vascular events. Blood vessels and their basement membrane, endothelial and muscular components gradually lose their integrity with aging. Older adults who have no typical risk factors, such as genetic predisposition, vascular risk factors, or previous TBI, can still develop AD. In this particular patient group, aging likely plays a predominant role in $\mathrm{AD}$ pathogenesis. The normally aging brain undergoes pathophysiological changes, including decreased cerebral blood flow and glucose metabolism, which might, at least in part, result from loss of integrity of brain microvessels, both on the arteriolar and venular side of the microcirculation. ${ }^{7,42}$ Epidemiological studies have shown that the incidences of both $\mathrm{AD}$ and CVD increase with aging $^{34-36}$ and some even claim that very late onset disease is part of the normal aging process. Therefore, the pathophysiological changes induced by aging could be etiologically related to, or even play an initiating role in, the pathogenesis of AD.

\section{Apolipoprotein E (APOE for gene; apoE for protein)}

ApoE is a plasma protein that transports lipids (e.g. cholesterol) and is associated with neuronal repair. The APOE gene, located on chromosome 19, has three allelic variations, and the occurrence rates in the general population are $8 \%$ for $\varepsilon 2$, $78 \%$ for $\varepsilon 3$, and $14 \%$ for $\varepsilon 4$, respectively, although this varies in different populations. ${ }^{39}$ The APOE- $\varepsilon 4$ allele is a genetic risk factor for both familial and sporadic late-onset $\mathrm{AD}^{43}$; this has been confirmed epidemiologically and pathologically. Heterozygous APOE- $\varepsilon 4$ carriers ( $\varepsilon 2 / \varepsilon 4$ or $\varepsilon 3 / \varepsilon 4)$ have $3-4$ times the risk of developing $\mathrm{AD}$, and homozygous carriers $(\varepsilon 4 / \varepsilon 4)$ have 10-12 times the risk. ${ }^{44}$ Patients with amnestic mild cognitive impairment (MCI) possessing at least one APOE- 44

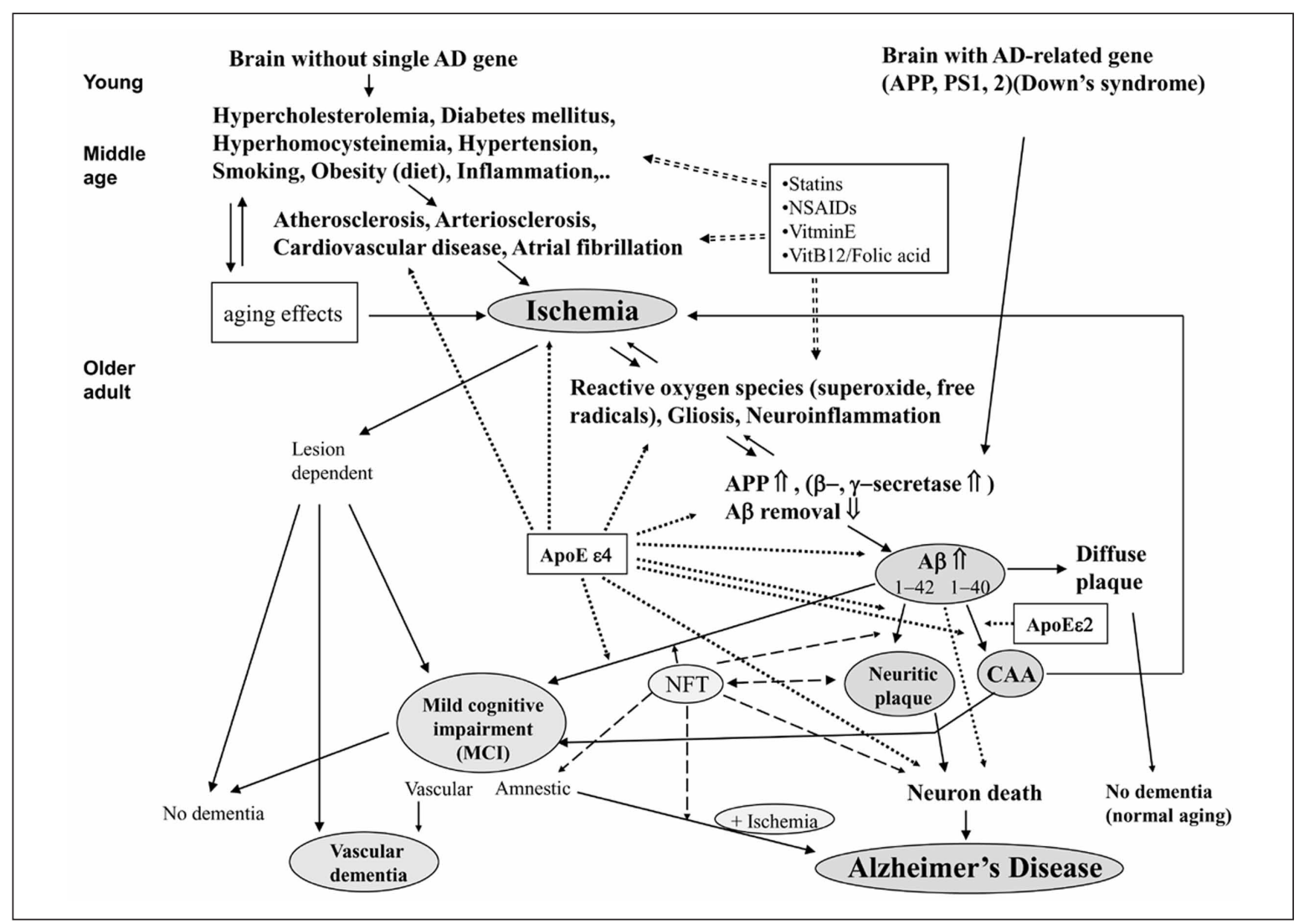

Figure 1: The schema shows the hypothetical pathway of Alzheimer's disease (AD). The main stream of this pathway is starting from the brain of individuals with no AD-related gene, i.e. sporadic AD, with mid-life vascular risk factors (hypercholesterolemia, diabetes mellitus, hyperhomocysteinemia, hypertension, smoking, obesity) through infarction (or hypoperfusion) and $\beta$-amyloid peptide $(A \beta)$ increase, resulting in neuritic plaques or cerebral amyloid angiopathy (CAA), and finally progressing to clinical AD. There is another pathway that starts from the brain of individuals with AD-related genes such as having a mutation in presenilin1, presenilin2, or amyloid precursor protein (APP) genes, or Down's syndrome. Sporadic $A D$ is one of the most important disorders for the older population. Studies have suggested an association between risk factors and subsequent development of $A D$. However, some of the $A D$ patients who do not have any risk factors may be affected by other aging effects that cause hypoperfusion in their brains. Once A $\beta$ peptide levels increase in the brain, these might (possibly via tau elevation) cause mild cognitive impairment (MCI) or AD. However, the pathway from $A \beta$ increases in to diffuse plaques may not cause dementia in older adults. 
allele have a $62 \%$ increased risk of progressing to $\mathrm{AD} .^{45}$ In comparison to non-carriers, they have lower mini mental status examination (MMSE) and higher (worse) Alzheimer Disease Assessment Scale-Cognitive (ADAS-cog) scores, and smaller hippocampal sizes. ${ }^{46}$ Most longitudinal analyses of nondemented individuals also reveal a greater decline in performance on a variety of cognitive tests in APOE- $\varepsilon 4$ positive subjects, ${ }^{47,48}$ showing that the presence of APOE- $\varepsilon 4$ is a risk factor for cognitive impairment. As pathological evidence, the ApoE protein is present in senile plaques and binds to the A $\beta(1-28)$ peptide. ${ }^{49}$ ApoE may have specific effects on the formation, aggregability, or clearance of $A \beta$, neurite outgrowth, and antioxidant activity. APOE- $\varepsilon 4$ is neurotoxic compared to $\varepsilon 3$, whereas $\varepsilon 2$ has protective effects. ${ }^{43}$ Increased risk for AD, decreased age of onset, increased senile plaque density, and decreased cholinergic neuron density, have all been shown to correlate with APOE- $\varepsilon 4$ allele copy numbers. ${ }^{50}$

APOE- $\varepsilon 4$ is also reported to be a risk factor for CVD including CAA. APOE- $\varepsilon 4$ was more common, not only in patients with $\mathrm{AD}(50-65 \%)$, but also in $\mathrm{VaD}(26 \%)$, than in nondemented controls (14\%). ${ }^{51}$ This allele is a risk factor for developing CAA and cerebrovascular pathology associated with $\mathrm{AD},{ }^{52}$ and is associated with the presence of CAA-related hemorrhages that are probably due to increased $A \beta$ deposition in the cerebral vessel walls. ${ }^{53,54}$ Although the APOE- 22 allele is protective for $\mathrm{AD},{ }^{55} \mathrm{APOE}-\varepsilon 2$ is believed to be a risk factor for CAA-related hemorrhages independent of AD, whereas APOE$\varepsilon 4$ is a risk factor dependent on concomitant AD..$^{56,57}$

The APOE- $\varepsilon 4$ allele is associated with elevations in total cholesterol levels and atherosclerosis relative to the $\varepsilon 3$ allele, while the $\varepsilon 2$ allele has the opposite effect. ${ }^{58}$ ApoE is the major cholesterol carrier in the brain, is very important in repairing damaged neuronal membranes, and binds to $A \beta .{ }^{59}$ It has been thought that interactions of ApoE and cholesterol might play a role in $A \beta$ secretion. Overall, APOE- $\varepsilon 4$ may make the brain more vulnerable; it could be one of the most important genetic risk factors for brain damage, such as by CVD and AD. For a comprehensive review of the role of APOE in AD, please see the article by Kim et al. ${ }^{60}$

\section{Hypercholesterolemia}

Hypercholesterolemia has received enormous attention because of its important etiological role in cardiovascular disease and therapeutic advances for its control. Epidemiological evidence has shown that hypercholesterolemia is also an important risk factor for AD. In the Rotterdam Study, high dietary intake of total fat and saturated fat increased the risk of dementia and $\mathrm{AD}$, whereas fish consumption, a source of omega3 polyunsaturated fatty acids, was inversely related to the incidence of dementia, particularly AD..$^{35,61}$ This study also found that there was no relationship between serum cholesterol level and risk of dementia within two years, while a longitudinal population-based study showed that mid-life hypercholesterolemia was associated with increased risk of late-life MCI and AD. ${ }^{62}$ Another study showed that hypercholesterolemia correlates with the presence of $A \beta$ deposition in the diffuse type of senile plaques, among subjects 40 to 55 years old. ${ }^{63}$ These epidemiological data are further supported by basic research studies suggesting that cholesterol may contribute to the development of AD pathology by altering APP processing. Simons et al showed in their in vitro studies that cholesterol level modulates the enzymatic processing of APP and A $\beta$ production. ${ }^{64}$ Moreover, in APP transgenic mice, diet-induced hypercholesterolemia accelerated $\mathrm{A} \beta$ pathology and decreased APP $\alpha$, a product of the non-amyloidogenic pathway. ${ }^{65}$ Cerebral A $\beta$ deposition occurred in APP transgenic mice on both atherogenic and normal diets, but only atherogenic diets impaired learning task performance. ${ }^{66}$ Hypercholesterolemia also increased the level of C-terminal fragments, the substrates for the subsequent intramembranous cleavage by the $\gamma$-secretase complex, resulting in an increase in $\mathrm{A} \beta 34,38,40$, and 42 production. ${ }^{65}$ Low cholesterol favors the non-amyloidogenic cleavage of APP by $\alpha$-secretase and leads to decreased A $\beta$ generation, whereas high cholesterol favors $\beta / \gamma$-secretase activity and thereby increases $A \beta$ production. ${ }^{64}$ The cholesterol transporter ABCA1 (ATP-binding cassette transporter) has become a focus of research, as it may connect cholesterol, ApoE, and $A \beta$. Lack of ABCA1 causes extremely low brain ApoE which gets stuck in amyloid plaques, and these abnormal APOE particles promote amyloid deposition in APP transgenic mice. ${ }^{67}$ Increasing $\mathrm{ABCA} 1$ activity may promote $\mathrm{A} \beta$ clearance.

Statins, therapeutic agents for the treatment of hypercholesterolemia, reduce serum cholesterol levels by inhibiting the rate limiting enzyme of cholesterol synthesis, 3hydroxy-3-methylglutaryl-CoA (HMG-CoA) reductase. Retrospective clinical studies have reported that the prevalence of diagnosed $\mathrm{AD}$ in patients taking statins was significantly lower than in those not taking statins. ${ }^{68-70}$ Both simvastatin and lovastatin reduce intracellular and extracellular $A \beta 42$ and $A \beta 40$ levels in cultures of hippocampal neurons and of mixed cortical neurons, and high-dose simvastatin induces a strong reduction of cerebral $A \beta 42$ and $A \beta 40$ levels in the cerebrospinal fluid and brain of guinea pigs. ${ }^{71}$ Furthermore, statins probably have other effects that antagonize $A \beta$ neurotoxicity, $A \beta$-induced vasoconstriction, and inflammation, ${ }^{72}$ working directly on the underlying pathology rather than through lipid-lowering effects. ${ }^{73}$ The FINRISK study showed that lipid-lowering treatment was related to decrease in dementia risk. ${ }^{74} \mathrm{~A}$ small randomized control trial (RCT) using atorvastatin $80 \mathrm{mg} /$ day for six months showed a significant positive effect on the ADAS$\operatorname{cog} .{ }^{75}$ However, two recent larger multicenter RCTs, one with atorvastatin $80 \mathrm{mg} /$ day for 13 months $^{76}$ and the other with simvastatin for 18 months, ${ }^{77}$ failed to show any benefit over placebo. A clinical trial of high-dose atorvastatin after transient ischemic attack or mild stroke found that it reduces stroke risk. ${ }^{78}$, Hence, it may be that cholesterol lowering medications may have a preventative benefit prior to clinical onset of AD through stroke prevention and possible vasoprotective and antiinflammatory effects. For a summary of cholesterol in AD, please see a review article by Shobab et al. ${ }^{79}$

\section{Hypertension}

Hypertension is an established risk factor for stroke, coronary heart disease, and $\mathrm{VaD}$. It is also evident that hypertension is associated with late-life cognitive impairment ${ }^{80,81}$ and increased amounts of senile plaques and NFTs. ${ }^{82}$ In a Swedish study, increased blood pressure at the age of 70 increased the risk of dementia between the ages of 80 and $85 .{ }^{83}$ A longitudinal 
prospective population-based study showed evidence of a relationship between hypertension and AD. In the Honolulu-Asia study, Japanese-American men with elevated mid-life blood pressure had a higher risk for $\mathrm{AD}$ at a follow-up period of 25 years ${ }^{84}$ A postmortem analysis of this Honolulu-Asia study showed that elevated systolic blood pressure $(>160 \mathrm{mmHg})$ in mid-life was associated with low brain weight at death and greater numbers of neuritic plaques in neocortex and hippocampus, while elevated diastolic blood pressure $(>95 \mathrm{mmHg}$ ) was associated with greater numbers of NFT in the hippocampus. ${ }^{85}$

There is evidence that antihypertensive drugs, such as calcium channel antagonists and angiotensin converting enzyme inhibitors (ACEI), may have some protective effects against development of dementia. A calcium channel antagonist was shown in an uncontrolled hypertensive population to reduce the emergence of dementia. ${ }^{86}$ Brain penetrating ACEI were found to reduce progression of cognitive decline in mild to moderate $\mathrm{AD}$ in one randomized control trial (RCT) ${ }^{87}$ However, ACEI failed to show a significant outcome in the Perindopril Protection Against Recurrent Stroke Study (PROGRESS) trial and in the Study on Cognition and Prognosis in the Elderly (SCOPE).$^{88}$ In vitro, ACEI increased $\mathrm{A} \beta 40$ and 42 secretion. ${ }^{89}$ Together, the data regarding the effectiveness of ACEI on cognitive decline in AD are inconclusive..$^{0}$ One study shows that angiotensin AT1receptor blockers (ARBs) are associated with lower risk of admission to a nursing home and death, and reduction in the incidence and progression of $\mathrm{AD}$ and dementia compared with ACEI. ${ }^{91}$ There is emerging evidence that ARBs may be more neuroprotective than ACEI because brain ACE also catabolizes cognition-enhancing brain peptides, amyloid peptides and converts toxic $A \beta 42$ into less toxic $A \beta 40 .{ }^{92}$ The ARBs increase AT2 and AT4 receptor agonists, angiotensin II and IV, respectively. AT2 receptor activation is important for both learning acquisition and recall of passive avoidance behavior, whereas AT1 is critical only for retrieval, by which the greater cognition-enhancing effects of ARBs can be explained. One of the ARBs, valsartan, has been shown to prevent the formation of high molecular weight oligomeric $\mathrm{A} \beta$ peptides in vitro, and is the only antihypertensive drug that shows evidence of prevention in vivo of $\mathrm{AD}$ pathological processes at present. ${ }^{93}$ Another study suggested that antihypertensive treatment, which was mainly based on use of beta-blockers, diuretics, or both, might reduce the risk of dementia. ${ }^{85}$

Subjects with combined high systolic blood pressure and high total cholesterol level at midlife had a significantly increased risk for $\mathrm{MCI}$ and $\mathrm{AD},{ }^{62}$ indicating that these are risk factors for both CVD and AD. $7,8,61$

\section{Diabetes mellitus}

Most studies have shown a positive association between diabetes mellitus and $\mathrm{AD}$. In a prospective population-based study, patients with diabetes mellitus had around a twofold increased risk of AD.$^{94,95}$ In a retrospective cohort study, diabetes mellitus was the strongest risk factor associated with late-life dementia. ${ }^{96}$ Patients with diabetes mellitus, especially those requiring insulin, had dementia more often than those without, ${ }^{61,97}$ and uncontrolled diabetes increased the risk of AD. ${ }^{98}$ The precise mechanisms remain unclear; however, diabetes mellitus related micro- and macrovascular changes could cause hypoperfusion, accelerating $\mathrm{A} \beta$ deposition, and possibly clinical AD.

Insulin resistance syndrome, characterized by chronic hyperinsulinemia, is associated with age-related memory impairment and $\mathrm{AD} .{ }^{99}$ In normal human adults, insulin increases cerebrospinal fluid (CSF) A $\beta 42$ levels in an age-dependent manner. ${ }^{100}$ Hyperinsulinemia results in down-regulation of insulin transport into the brain, thus causing decreased insulin in the brain. Patients with AD have lower CSF insulin levels and higher plasma insulin levels compared to healthy controls. ${ }^{99}$ In vitro, insulin increases the release of intracellular $A \beta 40$ and $42^{101}$, and regulates the expression of insulin-degrading enzyme, a protease critical for the efficient clearance of $A \beta .{ }^{99}$ Abnormally low brain insulin levels may result in increased intraneuronal accumulation of $A \beta$ and reduced $A \beta$ clearance. Hyperinsulinemia also increases CNS inflammation, ${ }^{102}$ which is thought to be another risk factor for AD.

\section{Obesity and Metabolic syndrome}

Obesity is another risk factor for AD, as well as for each of the vascular factors listed above (hypercholesterolemia, hypertension, and diabetes mellitus), and also increases the risk of CVD. In an 18 year follow-up study, baseline body mass index (BMI) was higher among subjects who developed AD than those who did not become demented. ${ }^{103}$ Obesity also increased the risk of AD in a community-based cohort of the Cache County study, ${ }^{104}$ and of dementia in a Swedish population-based twin study. ${ }^{104}$

Metabolic syndrome is characterized by the clustering of abdominal obesity, hypertriglyceridemia, low level of highdensity lipoprotein (HDL) cholesterol, hypertension, and hyperglycemia. ${ }^{105}$ Metabolic syndrome is associated with an increase of diabetes mellitus and cardiovascular disease ${ }^{106}$, both of which are linked to CVD and AD. As mentioned above, the combination of hypertension and hypercholesterolemia increased the risk of AD ${ }^{62}$ Similarly, subjects with the metabolic syndrome have an increased risk of developing AD. ${ }^{107}$

\section{Hyperhomocysteinemia}

Elevated plasma homocysteine has emerged as another vascular risk factor for both CVD and $\mathrm{AD}$, and can be a marker for low B12 or folate deficiency, though it can be elevated even when folate and B12 levels are within normal limits. It has been associated with an increased risk of atherosclerotic sequelae, including cardiovascular disease, ${ }^{108,109}$ carotid atherosclerosis, and stroke. ${ }^{110}$ Hyperhomocysteinemia has also been related to cerebral microangiopathy, endothelial injury and dysfunction, impaired nitric oxide activity, and increased oxidative stress. ${ }^{35,111}$ In cross-sectional and population-based cohort studies, elevated plasma homocysteine has been strongly associated with poor cognition, dementia, and development of AD. ${ }^{111-113}$ In those studies, the patients who developed dementia or AD had lower folate and vitamin B12 levels and higher homocysteine concentrations than the control subjects. ${ }^{112}$ This risk factor can, in part, be modifiable by supplementation of folic acid, vitamin B12 and vitamin $\mathrm{B} 6,{ }^{109}$ but so far no prospective studies have verified efficacy in stroke or dementia prevention. For a through overview, please see Garcia's review articles. ${ }^{109,114}$ 


\section{Tobacco smoking}

The possible relationship between cigarette smoking and AD is a controversial issue. Smoking has been well known to be an important risk factor for cardiovascular disease, and the Rotterdam Study showed that smoking resulted in a more than twofold increased risk of AD. ${ }^{61}$ However, some epidemiologic studies have reported a consistently inverse relationship between smoking and the incidence of AD. ${ }^{115}$ One community based study shows that current smoking is associated with increased risk of incident $\mathrm{AD}$ but no increase for former smokers. ${ }^{116}$ These results were supported by other studies showing that chronic exposure to nicotine may protect against $\mathrm{A} \beta$ pathology: acute and chronic nicotine administration has improved cognitive performance of not only healthy humans but also of patients with AD. ${ }^{117,118}$ Possible protective effects of nicotine against $\mathrm{A} \beta$ accumulation in the brain post mortem, in vitro and ex vivo have been reviewed elsewhere. ${ }^{119}$ Presumably, smoking has two opposing effects on the brain: protective effects through nicotinic receptor stimulation, and pathologic effects on cerebral blood vessels. Also, the conflicting epidemiological results may represent a survival effect due to smokers dying prematurely, before they can express dementia.

There are a number of other vascular risk factors implicated in AD and Vascular cognitive impairment. Each factor is worthy of a full paper in itself, which is not possible in this overview. However, it is worthwhile to briefly summarize our current understanding of the associations and possible mechanisms for each of those factors. ${ }^{120-122}$

\section{b) Role of vascular risk factors}

\section{Atherosclerosis, Arteriosclerosis, and Cardiovascular disease}

Atherosclerosis and arteriosclerosis may be keys in the association of CVD and AD. An autopsy study showed that atherosclerosis in the circle of Willis and its corresponding leptomeningeal arteries was significantly more severe in AD patients compared to a non-demented elderly group. ${ }^{123,124}$ Honig et al also showed that the presence of large-vessel CVD or atherosclerosis is strongly associated with an increased frequency of neuritic plaques. Moreover, this association persisted regardless of the presence or absence of cerebral infarction. ${ }^{125}$ In a large population study, severe atherosclerosis confirmed by ultrasound was associated with a high incidence of AD. ${ }^{126}$ A probable pathophysiological consequence associated with extensive and increasing stenosis in the circle of Willis or other large cerebral blood vessels is hypoperfusion. A study in transgenic mice also showed that the lesion area affected by aortic atherosclerosis is positively correlated with cerebral $A \beta$ deposits. ${ }^{66}$ Atherosclerotic cerebrovascular pathology itself might directly influence $A \beta$ deposition and the development of $\mathrm{AD}$ through a variety of mechanisms, i.e., subclinical ischemia, distal atheromicroembolization, increased parenchymal oxidative stress, and blood pressure dysregulation, which might affect the blood-brain barrier (BBB) through which $\mathrm{A} \beta$ may be transported from blood into brain tissue and vice versa. ${ }^{56}$ Cardiovascular diseases are a risk factor in the same way as result of atherosclerosis, and cardiac disease itself might result in CVD such as cardioembolism caused by atrial fibrillation. There is even recent evidence for impaired transmitral flow efficiency in diastolic filling on echocardiography in AD patients. ${ }^{127}$ Finally, a recent novel mechanism has been suggested by a study showing that tortuosity of the carotid artery termination, which anatomically abuts the substantia innominata where the cholinergic neurons are located, is increased in AD and is associated with a smaller volume of the substantia inominata and poor executive function. ${ }^{128}$

\section{Cerebral ischemia, hypoperfusion}

As a result of atherosclerosis and/or arteriosclerosis, cerebral ischemia or hypoperfusion occurs in patients who have vascular risk factors. Indeed, Snowdon et al. revealed that atherosclerosis of the circle of Willis was strongly associated with lacunar infarction, and those with the infarctions had poor cognitive function and a higher prevalence of dementia. ${ }^{12}$

Autopsy series have shown that $60-90 \%$ of AD cases exhibit various types of so-called silent cerebrovascular pathology including CAA, microvascular degeneration, and periventricular white matter (WM) lesions. Furthermore, a third of AD subjects show evidence of cerebral infarction at autopsy. ${ }^{9}$ The Nun study showed strong evidence that dementia is worse when both neuropathological features of $\mathrm{AD}$ and $\mathrm{VaD}$ coexist. White matter hyperintensities, which are thought to represent cerebral smallvessel disease revealed by magnetic resonance imaging (MRI), are detected more frequently and occupy more WM volume in AD patients than in normal controls. ${ }^{129}$ The dilation of periarterial spaces in the white matter in $\mathrm{AD}$ is greater in frequency and severity than in controls, and correlates with $\mathrm{A} \beta$ load in the cortex and with the severity of CAA. ${ }^{130}$ Even in demented subjects who did not fully meet the neuropathologic criteria for $\mathrm{AD}$, the severity of cognitive impairment or dementia is strongly correlated with the severity of brain infarction, and less $\mathrm{AD}$ pathology was needed with coexisting infarction to cause clinical dementia. ${ }^{12}$ Imaging-autopsy correlation studies suggest that periventricular WM disease may in fact be due to venous collagenosis exacerbating chronic periventricular hypoperfusion, and blood-brain barrier leakage, resulting in a chronic venous insufficiency syndrome, ${ }^{131,132}$ The HonoluluAsia Aging Study showed that the frequency of dementia increased with neuritic plaque density, and increased further in case of the presence of cerebrovascular lesions. ${ }^{11}$ Similarly, Esiri et al. showed that AD patients with additional CVD suffer significant reductions in cognitive examination scores, which can be seen even in patients with very mild pathological changes and normal or marginally reduced cognitive examination scores. ${ }^{10,133} \mathrm{CAA}$ in AD patients also showed a significant correlation with dementia severity. ${ }^{134}$ These studies suggest that strokes or cerebrovascular events worsen cognitive impairment and functional outcome in patients diagnosed with AD.

Experimental animal studies have indicated that brain ischemia or hypoperfusion appear to increase presence of $A \beta 1$ 40 and 1-42, and APP expression. ${ }^{13}$ Microglial activation, inflammation, and vulnerability to subsequent brain ischemia are also enhanced in transgenic mice. ${ }^{66,135}$ In a rodent model of stroke, intraventricular $\mathrm{A} \beta$ (25-35) injections interfere with infarct healing with expanding size instead of shrinkage. ${ }^{136}$ This would have strong implications for stroke recovery in $\mathrm{AD}$ patients. To better explore the relationship between pure brain ischemia and $\mathrm{A} \beta$ appearance, some studies have been done using 
non-transgenic rats to avoid the genetic effect on $A \beta$ genesis. APP and A $\beta$ appeared in the lesion as a result of induced ischemia, but disappeared during long-term observation. ${ }^{14}$ Moreover, even if the brain was saturated with $A \beta 1-42$ by injection after brain ischemia, it resulted in widespread diffuse amyloid plaques in hippocampus and cerebral cortex, and neuronal, glial, ependymal, endothelial and pericyte cell bodies were observed to be filled with $A \beta 1-42$ at the acute phase; however, no deposition of $\mathrm{A} \beta$ was observed after one year. ${ }^{137}$ Taken together, although brain ischemia does not result in permanent $A \beta$ deposits, it induces $A \beta$ production, which might have toxic effects on synapses in the hippocampus and elsewhere, causing memory loss and other cognitive problems.

\section{Reactive oxygen species (ROS), Inflammation, and Gliosis}

Reactive oxygen species (ROS) or superoxide is well known to be generated in the normal aging process, and as a consequence of ischemia. Reactive oxygen species gradually accumulate in the aging brain, damaging cell components, such as proteins, lipids, and DNA. ${ }^{138}$ If ischemia/reperfusion occurs, massive ROS and superoxide are generated, causing considerable damage in the brain. ${ }^{139}$ The amount of oxidized DNA base pairs was higher in leukocytes of patients with AD or MCI. ${ }^{140}$ NADPH oxidase, which causes ROS production in cerebral vessels, could be a mediator of the cerebrovascular dysregulation induced by aging, hypertension, and AD ${ }^{42}$ Animal studies have shown that decreased Superoxide dismutase-1 (SOD1), an enzyme that reduces the amount of potentially harmful free radicals, resulted in increased vascular damage after cerebral ischemia. ${ }^{139}$ In contrast, no endothelial dysfunction was found if SOD1 was overexpressed in APP transgenic mice. ${ }^{141}$ Hence, SOD1 might have a protective key role, not only against ischemic insults, but also against the toxic endothelial effects of APP. Reactive oxygen species appear to be very harmful in the aging and AD brain, and are currently targets for intervention.

Chronic inflammatory features such as activated microglia, reactive astrocytes, and other markers of inflammatory processes, including complement factors and cytokines, and acute-phase proteins, such as alpha-1 antichymotrypsin frequently colocalize with $\mathrm{A} \beta$ or $\beta$-amyloid precursor protein $(\beta$ APP) in cerebral ischemia and AD. ${ }^{135,136,142-144}$ Beta-APP and A $\beta$ are enhanced in reactive astrocytes, which appear in a similar distribution to AD pathologically, as seen in the hippocampus or CA1 and CA4 regions. ${ }^{14,142}$ Besides, A $\beta$ itself enhances pathological and inflammatory responses, and $A \beta$ toxicity enhances gliosis. ${ }^{136}$ Finally, both these basic research studies, and epidemiological studies have shown that anti-inflammatory drugs may slow the progression of $\mathrm{AD},{ }^{135,145}$ though no prospective trials have confirmed these findings. In contrast, some recent studies have shown that nonsteroidal antiinflammatory drugs (NSAIDs) have not been able to reduce the incidence of AAD or dementia, ${ }^{146}$ and may have adverse effects, with increased incidence of dementia, $\mathrm{AD}$, and neuritic plaques in a cohort of heavy NSAID users. ${ }^{147,148}$

According to the evidence described above, risk factors related to $\mathrm{AD}$ might result in $\mathrm{A} \beta$ cleavage change or decrease in $\mathrm{A} \beta$ clearance from the brain tissue, and cause $A \beta$ accumulation in the cells or the extracellular tissue in the brain. One study indicated that $\mathrm{A} \beta$ is rapidly produced and cleared from the CNS in human. ${ }^{149}$ Recently, a study suggested that $A \beta 1-40$ and 1-42 clearance from the brain is more important than $\mathrm{A} \beta$ production in late onset $\mathrm{AD}$ cases. ${ }^{32}$ Acceleration of $\mathrm{A} \beta$ production and impaired clearance, induced not by gene mutation but by environmental factors surrounding brain cells, could contribute to the development of clinical AD.

\section{ACETYlCholine (ACh) IN RELATion to AD}

The cholinergic deficit in AD may not only involve cholinergic innervation of cortical neurons but also lead to a loss of cholinergic innervation of cortical blood vessels. ${ }^{150}$ This vascular cholinergic deficit may cause cerebral hypoperfusion, which contributes to cognitive decline and neurodegeneration. Because cholinotoxicity, most likely related to toxic $\mathrm{A} \beta$ assemblies, is responsible for the axonal, hippocampal and cortical ACh denervation, ${ }^{119,151}$ ACh deficiency appearing in the $\mathrm{AD}$ brain is a key issue contributing to the initial symptoms and to subsequent disease progression.

The characteristics of cerebral blood flow (CBF) and glucose metabolism in the AD brain are evident in a very early stage of the disease process. ${ }^{152}$ However, it is not clear from the literature which occurs earlier, glucose hypometabolism or hypoperfusion. One PET study found an increased oxygen extraction fraction in the parietotemporal cortices in AD; however, the vascular transit time and vascular reactivity were well preserved in AD patients, whereas those indices showed marked worsening in $\mathrm{VaD}$ patients. ${ }^{153}$ It is possible that vascular factors contribute in the pathogenesis of $\mathrm{AD}$ at the capillary level such that vascular changes and insufficiency may occur before alteration in energy metabolism. By combining glucose PET, and single photon emission computed tomography imaging or arterial spin labelling MR, it may be possible to investigate these issues and detect $\mathrm{CBF}$ and brain glucose metabolism in the same patient to better understand the pathophysiological brain changes in preclinical stages of $\mathrm{AD}$. In future research, it may be worthwhile to study CBF and glucose metabolism pre- and postAD medications, such as acetylcholinesterase inhibitors, to demonstrate acute and chronic treatment differences in very early $\mathrm{AD}$ or MCI patients, and to see directly which changes occur earlier.

A $\beta$ - Biological EVIdence fOR the role of A $\beta$ 1-42 VASCULOTOXIN AND NEUROTOXIN

\section{a) $\mathbf{A} \boldsymbol{\beta}$ processing}

$\mathrm{A} \beta$ plaques and neurofibrillary tangles are key pathological features of $\mathrm{AD}$. Generally, the $\mathrm{A} \beta$ molecule is a peptide of 39 to 43 amino acids in vivo, although $\mathrm{A} \beta$ polypeptides have been prepared for experimental studies in vitro ${ }^{154}$, and rarely larger sizes in vivo ${ }^{155}$ Both $\mathrm{A} \beta 1-40$ and 1-42 are the main components of $A \beta$ accumulation in the brain with $A \beta 1-42$ being deposited in senile plaques in the brain parenchyma and $A \beta 1-40$ being deposited in the perivascular spaces around cerebral arteries, causing CAA.

$\mathrm{A} \beta$ is derived from the transmembrane protein APP. ${ }^{156}$ There are two APP cleavage pathways: the non-amyloidogenic pathway and the amyloidogenic pathway (Figure 2). In the nonamyloidogenic pathway, APP is cleaved by $\alpha$-secretase into 


\section{Amyloid precursor protein (APP)}

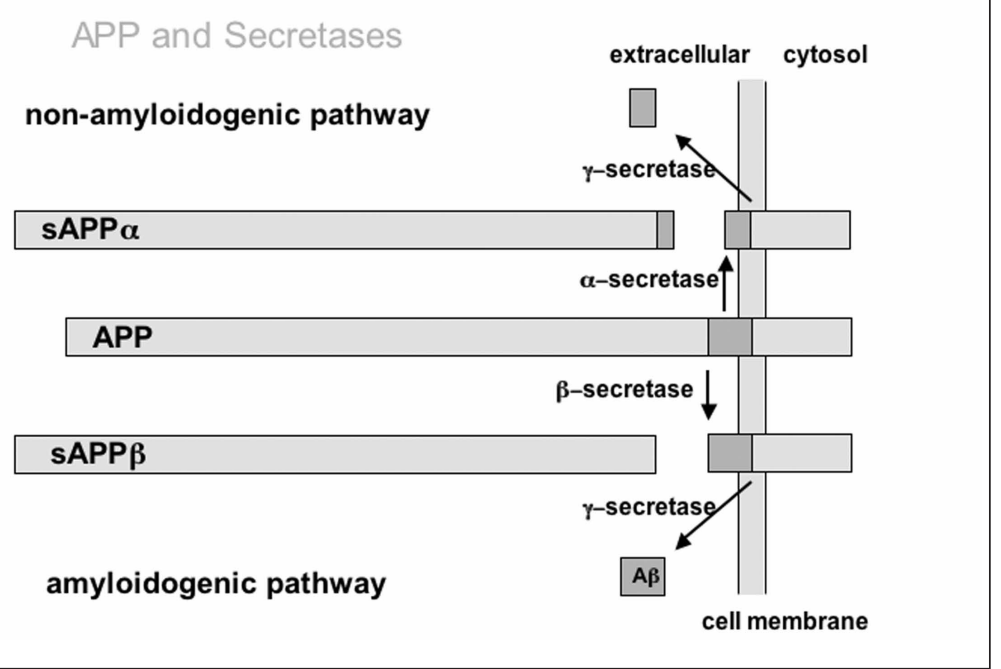

Figure 2: Amyloid precursor protein (APP) is a transmembrane protein. There are two APP cleavage pathways: the non-amyloidogenic pathway and the amyloidogenic pathway. In the non-amyloidogenic pathway, APP is cleaved by a-secretase into shorter fragments, that do not contain $A \beta$ or tend to polymerize, and therefore this pathway does not result in amyloid deposition in the brain. In the amyloidogenic pathway, APP is cleaved by $\beta$-secretase, which is also called $\beta$-amyloid cleaving enzyme $(B A C E)$, followed by $\gamma$-secretase cleavage. The BACE cleavage liberates $\beta$-APP that contains the $A \beta$ peptides fragment, and $\gamma$-secretase cleavage liberates the $A \beta 1$ 40 and 1-42 polypeptide (amyloidogenic) from $\beta$-APP.

shorter fragments that do not contain $A \beta$, or tend to polymerase and therefore this pathway does not result in amyloid deposition in the brain. In the amyloidogenic pathway, APP is cleaved by $\beta$ secretase ( $\beta$-amyloid cleaving enzyme - BACE), followed by $\gamma$ secretase cleavage. The BACE cleavage liberates $\beta$-APP that contains the $\mathrm{A} \beta$ peptides fragment, and $\gamma$-secretase cleavage liberates the $A \beta 1-40$ and 1-42 polypeptides (amyloidgenic) from $\beta$-APP. The A $\beta$ peptides are toxic in oligomeric forms and have a tendency to form fibrils and to aggregate in the brain, eventually depositing as plaques or CAA. The gene responsible for APP is located on chromosome 21. Trisomy of chromosome 21 causes Down's syndrome, a condition in which AD pathology is very common, with $A \beta$ deposition seen in the brain, often by age 40 , in a similar manner to late onset sporadic AD. One postmortem study suggests that the $A \beta$ deposition begins over a decade prior to the clinical symptoms of dementia in Down's syndrome. ${ }^{157}$

Approximately $2 \%$ of the $\mathrm{AD}$ patients possess an autosomal dominant genetic background, known as early-onset familiar $\mathrm{AD}$, as the onset is in the third to fourth decades. They have mutations in presenilin 1 (PS1), presenilin 2 (PS2), or APP genes with an extremely high penetrance rate. PS1 is an essential cofactor for $\gamma$-secretase activity ${ }^{158}$ and PS2 is the homologue of PS1. Therefore, these subgroups, including Down's syndrome, have a strong genetic inclination toward the increased production of A $\beta 1-42$, which appears to accelerate the pathogenic process of $\mathrm{AD}$. The other group, which is much more prevalent in older adults, is known as late-onset sporadic $\mathrm{AD}$. This group has no known $A \beta$-related genes directly related to $A \beta$ production, but rather appears for various reasons, including the presence of the ApoE- $\varepsilon 4$, to have difficulty with amyloid clearance. ${ }^{150}$

\section{b) $\mathbf{A} \boldsymbol{\beta}$ structure}

\section{Classification of $\boldsymbol{A} \boldsymbol{\beta}$ (Table)}

The $A \beta$ conformation is classified into two subgroups: amorphous and fibrillar $A \beta$. Amorphous $A \beta$ constitutes diffuse plaques, whereas fibrillar $A \beta$, which is a main component of neuritic plaques, is associated with neurotoxicity and neurodegeneration. Soluble and insoluble $A \beta$ are the other conformational classification. Soluble $A \beta$ includes amorphous $\mathrm{A} \beta$ (preamyloid) and insoluble $\mathrm{A} \beta$ consists of fibrillar $\mathrm{A} \beta$. In vivo, soluble $\mathrm{A} \beta$ exists in blood plasma, CSF, and the intracellular and extracellular spaces, and insoluble $A \beta$ mainly exists in the extracellular space in the brain.

Soluble and insoluble $A \beta$ levels are both increased in the $A D$ brain, but correlations between soluble $A \beta$ levels and the degree of synaptic loss and cognitive impairment are stronger. ${ }^{19,159}$ However, there appears to be little correlation between the numbers of amyloid plaques and the degree of cognitive impairment. ${ }^{160}$ These findings suggest that soluble $A \beta$ may initiate neurodegeneration and that $\mathrm{A} \beta$ plaques may not be the primary pathophysiology, but rather a reaction to or a result of $\mathrm{A} \beta$ accumulation, perhaps even as an epiphenomenon.

Basic studies showed that there are several different sizes of $A \beta$ assemblies (Table). The basic peptide for all assemblies is the monomeric $A \beta$. Low molecular weight $A \beta$ (LMW $A \beta$ ) is the minimum unit of $A \beta$ assembly. Other molecules are formed by aggregation, called oligomeric $\mathrm{A} \beta$, ADDLs (A $\beta$-derived diffuse ligands), protofibrils, and fibrils. ${ }^{19,161-163}$ These assemblies maintain equilibrium between monomers and protofibrils, but the final progress from protofibrils to fibrils appears to be an irreversible phenomenon. ${ }^{163,164} \mathrm{~A} \beta$ assemblies have the propensity to enlarge their size, especially once protofibrils have appeared, even when they are in equilibrium. ${ }^{17}$ Therefore, if 
Table: The names of $A \beta$ and those relationship between $A \beta$ aggregation molecules and characteristics of size, structure, neurotoxicity in vitro, and Congo red staining

\begin{tabular}{lllll}
\hline & structure & diameter $(\AA)$ & Neurotoxicity & Congo red \\
\hline Monomer A $\beta$ & & $0.1-0.2$ & - & - \\
LMW A $\beta$ & monomer $\sim$ dimer & $0.6 \sim$ & + & - \\
ADDLs & trimer 24 mer & 50 & + & + \\
Oligomer A $\beta$ & & + & + \\
Protofibrils & & $60-80$ & + & + \\
Protofilament (PF) & & $25-30$ & + & + \\
Fibrils & $5 \sim 6 \mathrm{PF}$ & $70-120$ & + & + \\
\hline
\end{tabular}

$\mathrm{A} \beta=$ amyloid $\beta ;$ LMWA $\beta=$ low molecular weight $\mathrm{A} \beta ; \mathrm{ADDLs}=\mathrm{A} \beta$-derived diffuse ligands

environmental conditions, such as $\mathrm{pH}, \mathrm{A} \beta$ and electrolyte concentrations, temperature, and incubation time are appropriate, the $\mathrm{A} \beta$ aggregates become larger and more difficult to dissolve. ${ }^{154}$ Amorphous $\mathrm{A} \beta$ appears at lower peptide concentrations and fibrillary $\mathrm{A} \beta$ at higher concentrations ${ }^{165}$, and there is a time-dependent relationship, i.e. longer times result in larger sizes. ${ }^{164}$

\section{Alpha-helix, $\beta$-sheet, and $\beta$-turn structures}

Conformations of monomers and dimers are mainly dominated by $\alpha$-helices. These switch to $\beta$-sheet structures for oligomers. ${ }^{154}$ Teplow suggested that ADDLs are the smallest form of protofibrils and would be expected to display some $\beta$ sheet structures but not large amounts. ${ }^{163}$ Protofibril formation involves substantial conformational rearrangement, during which unstructured, $\alpha$-helix, and $\beta$-strand elements transform into predominately $\beta$-sheet $/ \beta$-turn structures. ${ }^{163}$ Finally, protofibrils conform to $\beta$-sheet structures in large amounts, and form $A \beta$ fibrils, which are also composed of $\beta$-sheet structures. ${ }^{154}$ Fibrils and larger protofibrils $\beta$-sheet structures correlate with $\mathrm{A} \beta$ concentrations in vitro. ${ }^{17} \mathrm{~A} \beta$ fibrillogenesis is thought to be based on the $\beta$-sheet structure.

Senile plaques are a form of $\mathrm{A} \beta$ accumulation, and along with intercellular deposits hyperphosphorolated tau forming neurofibrillary tangles, are some of the earliest pathological changes appearing before neuronal loss occurs in both the aging and the AD brain. ${ }^{16}$ Senile plaques have two histologically different forms, which are thought to impact on disease symptoms and progression, classified as diffuse plaques and neuritic (or dense core) plaques. ${ }^{16}$ Diffuse plaques consist of amorphous $A \beta$, lack the $\beta$-sheet structure, and are not surrounded by dystrophic neurites. ${ }^{165}$ Neuritic plaques consist of fibrillar A $\beta$. Diffuse plaques are seen in normal aging, whereas neuritic plaques are found mostly in patients with $\mathrm{AD}$, but also in a small numbers in the normally aging brain. ${ }^{166}$ Therefore, it is very important to understand the role of both diffuse and neuritic plaques in neurotoxicity, neuronal death, and clinical symptoms. Since $A \beta \beta$-sheet content is related to insolubility and neurotoxicity, ${ }^{18,167}$ it has been thought that fibrillary $A \beta$ is extremely important in initiating AD pathology and for disease progression, making it an appropriate target for prevention and disease modification.

\section{c) $\mathbf{A} \boldsymbol{\beta}$ toxicity}

As indicated above, fibrillar $\mathrm{A} \beta$, protofibrils, and oligomer $\mathrm{A} \beta$ have the conformation of a $\beta$-sheet structure, which is specifically detected by Congo red or Thioflavin $\mathrm{T}$ staining. ${ }^{167}$ $\mathrm{A} \beta$ oligomers disrupt synaptic plasticity in vivo at concentrations found in human brain and CSF. ${ }^{18}$ Neurotoxicity of A $\beta$ molecules appears to be possible not only with large aggregates, but also in LMW A $\beta$, although it is not seen in monomers. ${ }^{18,167,168}$ Even though Congo red and Thioflavin T can detect oligomer $\mathrm{A} \beta$ and larger sizes, these dyes do not detect LMW A $\beta$ assemblies (see Table). ${ }^{17}$ Taken together, the neurotoxicity of $A \beta$ aggregation, through fibril formation, appears to lead to synaptic loss and eventually to neuronal death, correlating with memory impairment and other cognitive and neuropsychiatric symptoms.

$\mathrm{A} \beta 1-42$ is thought to be a more pathogenic toxic peptide than $\mathrm{A} \beta 1$-40. Intermolecular parallel $\beta$-sheet structure and $\beta$-turn formation play a role in the aggregation and neurotoxcity of $\mathrm{A} \beta 1-42$, and the $\mathrm{N}$ - and $\mathrm{C}$-terminal residues form intramolecular $\beta$-sheet structures which stabilize each molecule. ${ }^{169}$ In contrast, A $\beta 1-40$ does not form intramolecular $\beta$-sheet structures at the end of the $A \beta$ peptide residues. Therefore, $A \beta 1-42$ may have more propensity to accumulation and fibrillogenesis. Since $A \beta 1$ 40 is less fibrillogenic, its solubility is greater than $\mathrm{A} \beta 1-42$, and it normally drains from the brain along perivascular spaces more easily. ${ }^{170}$ The ratio of $A \beta 1-40$ to $A \beta 1-42$ likely contributes to the variability of disease progression with less tendency to form plaques with a higher $A \beta 40: 42$ ratio. For example, in hereditary cerebral hemorrhage with amyloidosis, which shows fewer parenchymal $\mathrm{A} \beta$ deposits compared to $\mathrm{AD}$, the $\mathrm{A} \beta$ 40:42 ratio is significantly higher than that in human AD postmortem brain tissue. ${ }^{171}$ In APP transgenic mice, a study showed that an elevated ratio of $\mathrm{A} \beta$ 40:42 favors the formation of CAA versus parenchymal plaques, and this is altered by ApoE- $\varepsilon 4 .{ }^{172}$ 
Therefore, the $A \beta$ 40:42 ratio may play an important role in where $A \beta$ aggregation occurs.

\section{Cerebral Amyloid Angiopathy (CAA)}

Cerebral amyloid angiopathy is another pathological finding commonly seen in the $\mathrm{AD}$ brain, and is considered an important cause of intracerebral hemorrhage as well as ischemic stroke especially in the older population who do not have any CVD risk factors. ${ }^{54}$ Cerebral amyloid angiopathy involves deposition of fibrillar A $\beta 1-40$ (Table) in cortical and leptomeningeal vessels, and is neuropathologically detected by Congo red staining. The prevalence of CAA is between 10-40\% in people who are 61-70 years old, whereas it is between 80 to $98 \%$ in $\mathrm{AD} .{ }^{173}$ Regarding the pathogenic role of CAA in $\mathrm{AD}$, it has been increasingly recognized that vascular pathology, such as lacunar infarcts and WM lesions, constitutes a risk factor for AD..$^{125,129,174}$ White matter hyperintensities have been described to have a similar posterior distribution as microbleeds, which predominantly appear in the occipital lobes, not only in CAA subjects but also in $\mathrm{AD}$ subjects. ${ }^{174,175} \mathrm{An}$ association between microbleeds and WM lesions is supported by the same risk factor, hypertension. ${ }^{176} \mathrm{An}$ important feature of CAA is degeneration of cells of the vascular walls. Endothelial cells and pericytes are involved in maintaining the BBB. ${ }^{177}$ Thus, degeneration of these cells may lead to a focal dysfunction of the BBB in AD. There is evidence that $A \beta$ accumulates in pericapillary and periarterial drainage pathways, ${ }^{178}$ and is cleared from the interstitial fluid to vessels by passing through the BBB. ${ }^{27,56} \mathrm{~A}$ compromised $\mathrm{BBB}$ may be required for deposition of $A \beta$ both in the brain parenchyma and in blood vessel walls. $A \beta$ originating from plasma may play a role in $\mathrm{A} \beta$ deposition in CAA when BBB integrity is compromised by other factors such as hypertension, atherosclerosis, and stroke. ${ }^{56}$ Soluble $\mathrm{A} \beta$ within the brain may also have toxic effects on vascular endotherium adversely affecting BBB..$^{27,179}$ In fact, increasing $A \beta$ levels may affect the BBB before pathological changes, such as CAA and $A \beta$ plaques appear. On the other hand, $A \beta$ produced by neurons may be the primary source of senile plaques, since neuronal $A \beta$ may not be transported by the interstitial fluid drainage towards the periphery along the perivascular spaces. ${ }^{170,180}$ High frequency of neuritic plaques and $\mathrm{AD}$ pathological criteria (CERAD, Braak, and NIA-Reagan-Institute) associated with increased CAA might be clinicopathological evidence of impaired $A \beta$ drainage in cerebellar vessels. ${ }^{125,181}$ Massive deposits of $A \beta$ in capillaries and precapillaries cause obliteration of the lumen, degeneration of endothelium, and basal lamina that lead to ischemia. ${ }^{170}$ Eventual damage of blood vessel walls results in microhemorrhages, impairment of brain perfusion, and strokes.

Cerebral amyloid angiopathy is thought to be implicated in AD-related vascular dysfunction in another way. A study showed that the structural and functional disruption of smooth muscle cells in the walls of leptomeningial vessels was affected by $A \beta$ deposition in transgenic mouse without muscle cell loss. The disruption of smooth muscle cell organization interfered with the ability of the vessel to respond appropriately to both an endothelial-dependent vasodilator (acetylcholine $[\mathrm{ACh}]$ ) and an endothelial-independent vasodilator (sodium nitroprusside). ${ }^{182}$ These results suggest that disorganized smooth muscle cells may contribute to vascular dysfunction, lead to cerebral hypoperfusion, and eventually result in impaired brain function. To summarize: on the one hand the amyloid cascade is driven by ischemia, and small vessel disease impairs amyloid clearance thereby facilitating its deposition both as interstitial plaques and along vessels. In turn, amyloid is a vascular toxin, and when it also accumulates around arteriolar walls, it can cause both ischemia and hemorrhage. It is both response to vascular risk factors and itself a vascular risk factor, which can lead to ischemic and hemorrhagic stroke and also dementia.

\section{A $\beta$ IMAGING IN VIVO}

The development of PET has allowed us to understand differences of CBF, glucose metabolism, and neurotransmitter function in the brain between normal subjects and AD patients. However, sensitivity, specificity, and positive and negative predictive values may not be sufficient, though new quantitative analysis techniques can identify a network of regions of glucose hypometabolism that form AD "signatures", which can be calculated for an individual patient and may have clinical utility. ${ }^{183,184}$

PET A $\beta$ imaging for early detection of AD pathology and for evaluation of the efficacy of antiamyloid therapies has been developed in the past decade. $\left[{ }^{11} \mathrm{C}\right] 2-\left(4^{\prime}\right.$-methylamino-phenyl)6-hydroxybenzothiazole $\left(\left[{ }^{11} \mathrm{C}\right] 6\right.$-OH-BTA-1, or $\left[{ }^{11} \mathrm{C}\right]$ Pittsburgh compound $\mathrm{B}$ or $\mathrm{PIB})$ and $\left[{ }^{11} \mathrm{C}\right] 4-\mathrm{N}$-methylamino-4'hydroxystilbene $\left(\left[{ }^{11} \mathrm{C}\right] \mathrm{SB}-13\right)$ have been reported as $\mathrm{A} \beta$ detecting radiotracers in AD patients (Figure 3).24,26,185 Since the half-life of $\left[{ }^{11} \mathrm{C}\right]$-labeled ligands is short $(20.4 \mathrm{~min}),\left[{ }^{18} \mathrm{~F}\right]-$ labeled ligands with a longer half-life $(109.7 \mathrm{~min})$ are being developed for clinical use in the majority of institutions that lack a cyclotron. ${ }^{186}$ There are three radioligands, $\left[{ }^{18} \mathrm{~F}\right] \mathrm{AH} 110690$ (flutemetamol), ${ }^{187}\left[{ }^{18} \mathrm{~F}\right] \mathrm{BAY} 94-9172$ (florbetaben), ${ }^{188}$ and $\left[{ }^{18} \mathrm{~F}\right] \mathrm{AV}-45$ (florbetapir), ${ }^{189}$ which perform comparably to $\left[{ }^{11} \mathrm{C}\right] \mathrm{PIB} .{ }^{23}$ The Alzheimer's Disease Neuroimaging Initiative (ADNI) is now utilizing $\left[{ }^{18} \mathrm{~F}\right] \mathrm{AV}-45$ so that participating sites can have an access to A $\beta$ PET imaging without a cyclotron. (http://www.adni-info.org/Home.aspx) Florbetapir is furthest along in its development ${ }^{189,190}$ and recently achieved FDA labelling for clinical use in detecting cerebral amyloid depostion. ${ }^{191}$ The development of these radiotracers was based on Thioflavin $T$, which detects $A \beta$ with a $\beta$-sheet structure. Hence these ligands also label fibrillar amyloid in plaques or vessels. This also means that it may be difficult to detect preclinical neuropathology of $\mathrm{AD}$ in its earliest phases as these radioligands cannot detect LMW A $\beta$ or soluble $A \beta$ species.

High magnetic field strength magnetic resonance imaging (MRI) can detect $\mathrm{A} \beta$ deposition in transgenic mice, ${ }^{192}$ but to our knowledge, only one report has claimed to show putative $A \beta$ plaques using 7 Tesla MRI in in vivo human brain, ${ }^{193}$ in a small series ten AD subjects, ten age-matched normal controls, and ten young normal subjects. The putative plaques were seen in the parietal cortex in all cases of $\mathrm{AD}$ and in two out of ten agematched controls.

Postmortem neuropathologic examinations have shown senile plaques and NFTs in the brains of subjects with very early $\mathrm{AD}, \mathrm{MCI}$, and even normal aging, and accumulation of $\mathrm{A} \beta$ may begin in the brains of $\mathrm{AD}$ and Down's syndrome patients 10 to 40 years prior to the onset of clinical dementia symptoms. ${ }^{157,194}$ $A \beta$ deposition progresses by a stepwise involvement of 


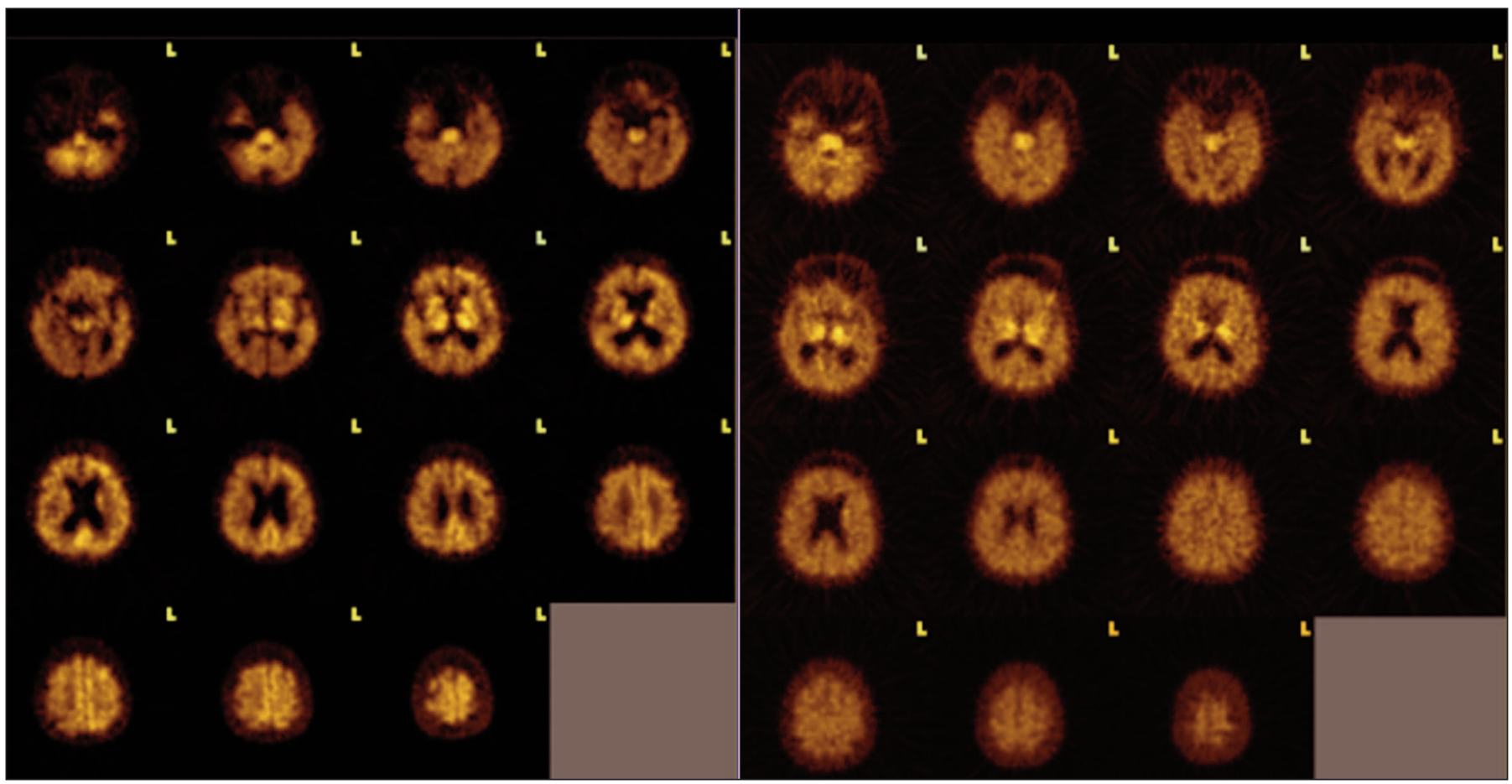

Figure 3: : $\left[{ }^{11}\right.$ C]SB-13 PET data in a 77-year-old mild Alzheimer's disease patient (left) versus a 74-year-old age-matched healthy comparison subject (right). The A $\beta$ binding potential (Ichise noninvasive model $\left.R_{v}\left(k_{3} / k_{4}\right)^{26}\right)$ is increased in the frontal and posterior temporal-inferior parietal association cortices in the Alzheimer's disease patient.

connected anatomical subfields. ${ }^{195}$ Thal and colleagues have found a hierarchical pattern of $\mathrm{A} \beta$ deposition in the brains of $\mathrm{AD}$ subjects with and without dementia. ${ }^{196}$ They found that $A \beta$ deposition begins in the whole neocortex (Phase 1) and expands into deeper brain tissues such as the allocortex (Phase 2), the diencephalic nuclei (Phase 3), the brainstem nuclei (Phase 4), and finally the cerebellum (Phase 5). This hierarchy was also found in the brains of APP or PS1 transgenic mice. ${ }^{197}$ A $\beta$ deposits become apparent before clinical symptoms appear, and clinically proven $\mathrm{AD}$ is a late stage of this process. They also found that AD-related pathology cases (clinically not demented but pathology positive) show less expansion of $A \beta$-deposition than demented AD cases, but more than normal cases. This evidence shows that once patients progress to MCI or very mild dementia such as a Clinical Dementia Rating scale score of 0.5 , the pathological changes are already severe, and conversely that as their symptoms progress further, the AD pathology is already severe without much further progression. This underlines the importance of preclinical detection of AD pathology using $\mathrm{A} \beta$ PET imaging. Indeed, $A \beta$ pathology has been detected using PET imaging in MCI subjects. ${ }^{46,198}$ However, MCI is still an equivocal heterogeneous group, and a PET study showed subjects with and without detectable $A \beta$ pathology. ${ }^{198}$ Because more than one third of older persons with MCI developed AD during an average follow-up period of about five years ${ }^{45}$, noninvasive preclinical $A \beta$ imaging with the combination of $\mathrm{MRI} /$ computed tomography has the possibility to discriminate a MCI-AD progressive group from a MCI-AD non-progressive group. ${ }^{199,200}$ The cumulative evidence of follow-up studies in
MCI (mostly amnestic) and AD subjects using $\left[{ }^{11} \mathrm{C}\right] \mathrm{PIB}$, $\left[{ }^{18} \mathrm{~F}\right] \mathrm{AH} 110690,\left[{ }^{18} \mathrm{~F}\right] \mathrm{BAY} 94-9172$, and $\left[{ }^{18} \mathrm{~F}\right] \mathrm{AV}-45$ showed a cognitive decline in amyloid positive MCI subjects. ${ }^{201}$ Villain et al has just reported that both PIB-positive and -negative subjects showed a significant increase in $A \beta$ deposition, with this increase being significantly higher in PIB-positive individuals. ${ }^{202}$ Together, $A \beta$-positivity on PET appears to be a good predictor of progression from MCI to AD. A $\beta$ imaging also would make it possible to recognize preclinical phases of $\mathrm{AD}$, and to determine the extent of $A \beta$ pathology distribution in demented patients. The most important role of in vivo $\mathrm{A} \beta$ imaging will likely be in conjunction with the development of several new classes of antiamyloid therapies, which have entered the clinical trial stage (see the following section). It may improve the efficacy of $A \beta$ therapies by providing an important surrogate outcome, namely reduction of amyloid burden..$^{203}$

T2*-weighted gradient-recalled echo (GRE) imaging or susceptibility-weighted imaging has been recently used to detect CAA-associated cerebral microbleeds. ${ }^{174,176,204}$ Since there is no difference between $A \beta$ in plaques and in vessel walls in terms of $\beta$-sheet structure, the utility of topographical differences in $A \beta$ binding to discriminate between these two pathological entities has been studied. A study using $\left[{ }^{11} \mathrm{C}\right] \mathrm{PIB}$ found the occipital-toglobal PIB retention was greater in CAA subjects compared to AD subjects. ${ }^{175}$

\section{Treatment For AD linkage With A $\beta$}

There are many approaches to treatment of AD. So far, the only approved treatments aim to slow decline of behavioural and 
cognitive symptoms, which includes acetylcholine esterase inhibitors (AChEIs: tacrine, donepezil, rivastigmine, galantamine) and the N-methyl-D-aspartate receptor antagonist memantine. ${ }^{205}$ These drugs provide modest symptomatic relief with evidence of some benefit at different stages of severity, though randomized controlled studies to determine longer-term benefit are very difficult to do, so the objective evidence base is slim. Other approaches that have been tried unsuccessfully include NSAIDs and vascular risk reduction medications such as antihypertensives and cholesterol-lowering agents (e.g., statins), vitamins (e.g., vitamin $\mathrm{E}$ and $\mathrm{C}$ ), and hormones such as estrogen, testosterone, and insulin. ${ }^{204}$ Since some aspects of preclinical neuropathological initiation of $\mathrm{AD}$ are understood, researchers have been investigating specific treatments targeting key toxic misfolded proteins seen in $A D$ at autopsy, namely $A \beta$ and hyperphosphorylated tau, the main component of NFT. Because $A \beta$ increase is thought to constitute the earliest change in the preclinical AD brain, a huge effort is currently underway to alter $\mathrm{A} \beta$ formation or clearance.

$\mathrm{A} \beta$ modification therapies are classified into therapeutics that target amyloid production, aggregation, and/or degradation. Some of them are now being tested in on-going clinical trials..$^{206}$ It has been suggested that AChEIs may stimulate the nonamyloidogenic $\alpha$-secretase cleavage of APP. ${ }^{119}$ BACE inhibitors include TAK-070 and BMS has one in development. Gammasecretase inhibitors include: LY450139, nonpeptidic isocoumarin compounds (JLK inhibitors) now discredit, STI571 (Gleevec), and NSAIDs. The $\gamma$-secretase modulator Rflurbiprofen looked promising in a phase II trial, ${ }^{207}$ but failed in phase III. ${ }^{208}$

Amyloid aggregation targeting therapies by antifibrillization include the glycosaminoglycan mimetic NC-531 (Alzhemed) ${ }^{209}$, PBT-2, PPI-1019, and TTP-448. The Phase II Alzhemed trial showed reduction of CSF A 342 and stabilization of cognitive function in mild AD. However, the phase III trial failed to show efficacy (http://www.bellushealth.com/en/newsroom/?rkey= $1506228356 \&$ view $=96347-2 \&$ Start $=0 \& h t m=0$ ).

An oral deaggregating agent by McLaurin and collegues is a cyclohexanehexol stereoisomer or scyllo-inositol, which blocks the accumulation of $\mathrm{A} \beta$ oligomers, and reduces $\mathrm{AD}$-like behavioral deficits, AD-like neuropathology, and mortality in a transgenic mouse model of AD. ${ }^{210}$ Because this drug is able to alter $\mathrm{A} \beta$ pathology even after the symptoms appear, it may be useful not only in preclinical $A D$ subjects but also in $A D$ patients. A phase II trial was performed for this drug in mild to moderate AD. No clinical significance was shown, but there were some promising trends for some clinical outcomes and CSF amyloid levels in exploratory analysis.

Immunization is another $A \beta$ modification therapy option that has been studied in both transgenic mice and AD patients. Although immunization succeeded in modulating cognitive problems ${ }^{211}$ and reduced $\mathrm{A} \beta$ plaques in APP transgenic mice, ${ }^{212}$ the studies using immunization with $\mathrm{A} \beta 42$ (AN1792) in $\mathrm{AD}$ patients had to be terminated prematurely owing to brain hemorrhage $^{213}$ and/or meningoencephalitis. ${ }^{214,215}$ Pathological evidence of the post-immunization patients showed that, although there was no effect on the frequency and severity of CAA per se, hemorrhages could clearly be attributed to amyloidladen blood vessels, and bleeding only occurred in brain areas affected by CAA. ${ }^{213}$ Cerebral amyloid angiopathy is therefore assumed to be a contraindication to $A \beta$ immunization and screening for this prior to immunization therapy might improve results. The AN1792 trial in AD patients revealed decreased brain plaque burden at autopsy. However, there was no evidence for improvement of survival or severity of dementia even though some treatment responders showed some improvement in memory testing. ${ }^{216} \mathrm{~A}$ gantenerumab Phase II trial showed some efficacy in removing $A \beta$ from the brain parenchyma in a dose dependent manner.

Passive immunization with a humanized recombinant $A \beta$ monoclonal antibody directed against the $\mathrm{N}$ terminus of $\mathrm{A} \beta$ (AAB-001 or Bapineuzumab) is also under investigation and has entered a phase III clinical trial (http://clinicaltrials.gov/ ct2/show/NCT00574132?term=Bapineuzumab\&rank=1). There are also some other ongoing Phase II-III immunization trials underway (Refer to Clinicaltrials.gov). For further detail in the immunotherapy in AD and clinical trials, please see a Delrieu's review article ${ }^{217}$ and Townsend's review article..$^{206}$

Also new consensus MRI guidelines have been developed to determine eligibility and for monitoring patients for clinical trials of anti-amyloid therapies, and eventually for clinical use, should this approach reach approval for clinical use. Specifically, Fluid Attenuated Inversion Recovery imaging (FLAIR) to detect vasogenic edema and T2*-weighted gradient echo (GRE) to detect microbleeds are required at baseline and for safety monitoring as described in Sperling et al, 2011. ${ }^{218}$

\section{Conclusions}

Considerable progress has been made in AD-related research. However, it is, as yet, unclear what underlies the association between vascular risk factors and $\mathrm{AD}$. We know that sporadic $\mathrm{AD}$ is a multifactorial disorder at old age, and vascular pathology contributes to or causes the dementia syndrome. The principal pathological mechanism responsible for $A \beta$ has not yet been identified; however, substantial evidence suggests that cardiovascular risk factors and CVD-related effects are involved. We hypothesize that sporadic $\mathrm{AD}$ is initiated by vascular factors in early life causing brain hypoperfusion and/or inflammation, which precede the $A \beta$ increase and aggregation, which may also cause brain hypoperfusion and $\mathrm{A} \beta$ drainage dysfunction, and eventually cause the neurodegenerative process. Therefore, firstly, addressing life style, and controlling vascular, i.e. AD, risk factors, is very important for primary prevention. Secondly, since $A \beta$ already appears widespread in the brain preclinically, detecting $\mathrm{A} \beta$ accumulation in vivo, by applying $\mathrm{A} \beta$ PET imaging in the preclinical or early stages, combined with targeting $A \beta$ reducing therapy, may be more important for secondary prevention of $\mathrm{AD}$ to succeed. Further investigation is needed for assessing $\mathrm{AD}$ and its treatment, and in order for disease modifying therapy to become clinically available.

\section{ACKNOWLEDGMENTS}

Dr. Honjo received salary support from the Brill Chair in Neurology, University of Toronto. Dr. Black's research has been supported by the Canadian Institutes of Health Research (Grant \#13129), the Heart and Stroke Foundation Canada, the Alzheimer's Association, US, Alzheimer Society of Canada, National Institute of Health, and Canadian Stroke Network. Dr. 
Verhoeff's research has been supported by the Alzheimer Society of Canada, the Alzheimer Society of Saskatchewan, the Alzheimer's Association, the Canadian Institutes of Health Research, and the Scottish Rite Charitable Foundation of Canada.

\section{REFERENCES}

1. Alzheimer's Disease International[homepage on the Internet]. London, UK: World Alzheimer report 2011. The benefits of early diagnosis and intervention. [updated 2011 Sep; cited 2012 Jun 17]. Available from: http://www.alz.co.uk/research/world-report2011/.

2. Alzheimer Society of Canada[homepage on the Internet]. Toronto, Canada: Rising tide: The impact of dementia on Canadian society. [updated 2012 Apr 19; cited 2012 Apr 23]. Available from: http://www.alzheimer.ca/en/Get-involved/Raise-yourvoice/Rising-Tide.

3. Alzheimer's Association. Alzheimer's disease facts and figures. Alzheimers Dement. 2010;6:158-94.

4. Hebert LE, Scherr PA, Bienias JL, Bennett DA, Evans DA. Alzheimer disease in the US population: prevalence estimates using the 2000 census. Arch Neurol. 2003;60:1119-22.

5. RTI International[homepage on the Internet]. Economic studies program: Disease-Specific estimates of direct and indirect costs and NIH support. Fiscal Year 2000 Update. [updated 2007 Jul 25; cited 2012 Jun 17]. Available from: http://ospp.od.nih.gov/ ecostudies/COIreportweb.htm.

6. Roth M. The natural history of mental disorder in old age. J Ment Sci. 1955;101:281-301.

7. de la Torre JC. Alzheimer disease as a vascular disorder: nosological evidence. Stroke. 2002;33:1152-62.

8. Gorelick PB. Risk factors for vascular dementia and Alzheimer disease. Stroke. 2004;35:2620-2.

9. Kalaria RN. The role of cerebral ischemia in Alzheimer's disease. Neurobiol Aging. 2000;21:321-30.

10. Esiri MM, Nagy Z, Smith MZ, Barnetson L, Smith AD. Cerebrovascular disease and threshold for dementia in the early stages of Alzheimer's disease. Lancet. 1999;354:919-20.

11. Petrovitch H, Ross GW, Steinhorn SC, et al. AD lesions and infarcts in demented and non-demented Japanese-American men. Ann Neurol. 2005;57:98-103.

12. Snowdon DA, Greiner LH, Mortimer JA, Riley KP, Greiner PA, Markesbery WR. Brain infarction and the clinical expression of Alzheimer disease. The Nun Study. JAMA. 1997;277:813-17.

13. Kalaria RN, Bhatti SU, Lust WD, Perry G. The amyloid precursor protein in ischemic brain injury and chronic hypoperfusion. Ann N Y Acad Sci. 1993;695:190-3.

14. Nihashi T, Inao S, Kajita Y, et al. Expression and distribution of beta amyloid precursor protein and beta amyloid peptide in reactive astrocytes after transient middle cerebral artery occlusion. Acta Neurochir (Wien). 2001;143:287-95.

15. Honjo K, van Reekum R, Verhoeff NP. Alzheimer's disease and infection: do infectious agents contribute to progression of Alzheimer's disease? Alzheimers Dement. 2009;5:348-60.

16. Braak H, Braak E. Frequency of stages of Alzheimer-related lesions in different age categories. Neurobiol Aging. 1997;18:351-7.

17. Walsh DM, Hartley DM, Kusumoto Y, et al. Amyloid beta-protein fibrillogenesis. Structure and biological activity of protofibrillar intermediates. J Biol Chem. 1999;274:25945-52.

18. Walsh DM, Klyubin I, Fadeeva JV, et al. Naturally secreted oligomers of amyloid beta protein potently inhibit hippocampal long-term potentiation in vivo. Nature. 2002;416:535-9.

19. Klein WL, Krafft GA, Finch CE. Targeting small Abeta oligomers: the solution to an Alzheimer's disease conundrum? Trends Neurosci. 2001;24:219-24.

20. McKhann GM, Knopman DS, Chertkow H, et al. The diagnosis of dementia due to Alzheimer's disease: recommendations from the National Institute on Aging and the Alzheimer's Association workgroup. Alzheimers Dement. 2011;7:263-9.

21. Chertkow H, Black S. Imaging biomarkers and their role in dementia clinical trials. Can J Neurol Sci. 2007;34:S77-83.
22. Drzezga A. Amyloid-plaque imaging in early and differential diagnosis of dementia. Ann Nucl Med. 2010;24:55-66.

23. Herholz K, Ebmeier K. Clinical amyloid imaging in Alzheimer's disease. Lancet Neurol. 2011;10:667-70.

24. Klunk WE, Engler H, Nordberg A, et al. Imaging brain amyloid in Alzheimer's disease with Pittsburgh Compound-B. Ann Neurol. 2004:55:306-19.

25. Shoghi-Jadid K, Small GW, Agdeppa ED, et al. Localization of neurofibrillary tangles and beta-amyloid plaques in the brains of living patients with Alzheimer disease. Am J Geriatr Psychiatry. 2002;10:24-35

26. Verhoeff NP, Wilson AA, Takeshita S, et al. In-vivo imaging of Alzheimer disease beta-amyloid with [11C]SB-13 PET. Am J Geriatr Psychiatry. 2004;12:584-95.

27. Bell RD, Zlokovic BV. Neurovascular mechanisms and blood-brain barrier disorder in Alzheimer's disease. Acta Neuropathol. 2009; 118:103-13.

28. American Psychiatric Association; Diagnostic and statistical manual of mental disorders. 4th ed. Text revision. Washington, D.C.: 2000. p. $135-80$

29. Roman GC, Tatemichi TK, Erkinjuntti T, et al. Vascular dementia: diagnostic criteria for research studies. Report of the NINDSAIREN International Workshop. Neurology. 1993;43:250-60.

30. Neuropathology Group. Medical Research Council Cognitive Function and Aging Study. Pathological correlates of late-onset dementia in a multicentre, community-based population in England and Wales. Neuropathology Group of the Medical Research Council Cognitive Function and Ageing Study (MRC CFAS). Lancet. 2001;357:169-75.

31. Selkoe DJ. Toward a comprehensive theory for Alzheimer's disease. Hypothesis: Alzheimer's disease is caused by the cerebral accumulation and cytotoxicity of amyloid beta-protein. Ann N Y Acad Sci. 2000;924:17-25.

32. Mawuenyega KG, Sigurdson W, Ovod V, et al. Decreased clearance of CNS beta-amyloid in Alzheimer's disease. Science. 2010;330: 1774.

33. de la Torre JC. Critically attained threshold of cerebral hypoperfusion: the CATCH hypothesis of Alzheimer's pathogenesis. Neurobiol Aging. 2000;21:331-42.

34. Canadian study of health and aging: study methods and prevalence of dementia. CMAJ 1994;150:899-913.

35. Breteler MM. Vascular risk factors for Alzheimer's disease: an epidemiologic perspective. Neurobiol Aging. 2000;21:153-60.

36. Jorm AF, Korten AE, Henderson AS. The prevalence of dementia: a quantitative integration of the literature. Acta Psychiatr Scand. 1987;76:465-79.

37. Rogaeva E, Meng Y, Lee JH, et al. The neuronal sortilin-related receptor SORL1 is genetically associated with Alzheimer disease. Nat Genet. 2007;39:168-77.

38. Morgan K. Commentary: the three new pathways leading to Alzheimer's disease. Neuropathol Appl Neurobiol. 2011;37: 353-7.

39. Menzel HJ, Kladetzky RG, Assmann G. Apolipoprotein E polymorphism and coronary artery disease. Arteriosclerosis. 1983;3:310-15.

40. De Strooper B. Loss-of-function presenilin mutations in Alzheimer disease. Talking point on the role of presenilin mutations in Alzheimer disease. EMBO Rep. 2007;8:141-6.

41. Revesz T, Holton JL, Lashley T, et al. Genetics and molecular pathogenesis of sporadic and hereditary cerebral amyloid angiopathies. Acta Neuropathol. 2009;118:115-30.

42. Black S, Iadecola C. Vascular cognitive impairment: small vessels, big toll: introduction. Stroke. 2009;40:S38-9.

43. Slooter AJ, van Duijn CM. Genetic epidemiology of Alzheimer disease. Epidemiol Rev. 1997;19:107-19.

44. Farrer LA, Cupples LA, Haines JL, et al. Effects of age, sex, and ethnicity on the association between apolipoprotein E genotype and Alzheimer disease. A meta-analysis. APOE and Alzheimer Disease Meta Analysis Consortium. JAMA. 1997;278:1349-56.

45. Aggarwal NT, Wilson RS, Beck TL, Bienias JL, Berry-Kravis E, Bennett DA. The apolipoprotein E epsilon4 allele and incident Alzheimer's disease in persons with mild cognitive impairment. Neurocase. 2005;11:3-7. 
46. Farlow MR, He Y, Tekin S, Xu J, Lane R, Charles HC. Impact of APOE in mild cognitive impairment. Neurology. 2004;63: 1898-901.

47. Hsiung GY, Sadovnick AD, Feldman H. Apolipoprotein E epsilon4 genotype as a risk factor for cognitive decline and dementia: data from the Canadian Study of Health and Aging. CMAJ. 2004; 171:863-7.

48. Small BJ, Rosnick CB, Fratiglioni L, Backman L. Apolipoprotein E and cognitive performance: a meta-analysis. Psychol Aging. 2004;19:592-600.

49. Strittmatter WJ, Weisgraber KH, Huang DY, et al. Binding of human apolipoprotein $\mathrm{E}$ to synthetic amyloid beta peptide: isoform-specific effects and implications for late-onset Alzheimer disease. Proc Natl Acad Sci USA. 1993;90:8098-102.

50. Blass JP, Poirier J. Pathophysiology of the Alzheimer syndrome. In: Gauthier S, editor. Clinical diagnosis and management of Alzheimer's disease. London: Martin Dunitz; 1996. p. 17-31.

51. van der Flier WM, Pijnenburg YA, Fox NC, Scheltens P. Earlyonset versus late-onset Alzheimer's disease: the case of the missing APOE varepsilon4 allele. Lancet Neurol. 2010;10: 280-8.

52. Premkumar DR, Cohen DL, Hedera P, Friedland RP, Kalaria RN. Apolipoprotein E-epsilon4 alleles in cerebral amyloid angiopathy and cerebrovascular pathology associated with Alzheimer's disease. Am J Pathol. 1996;148:2083-95.

53. Greenberg SM, Briggs ME, Hyman BT, et al. Apolipoprotein E epsilon 4 is associated with the presence and earlier onset of hemorrhage in cerebral amyloid angiopathy. Stroke. 1996;27: 1333-7.

54. O'Donnell HC, Rosand J, Knudsen KA, et al. Apolipoprotein E genotype and the risk of recurrent lobar intracerebral hemorrhage. N Engl J Med. 2000;342:240-5.

55. Corder EH, Saunders AM, Risch NJ, et al. Protective effect of apolipoprotein $\mathrm{E}$ type 2 allele for late onset Alzheimer disease. Nat Genet. 1994;7:180-4.

56. Rensink AA, de Waal RM, Kremer B, Verbeek MM. Pathogenesis of cerebral amyloid angiopathy. Brain Res Brain Res Rev. 2003; 43:207-23.

57. McCarron MO, Nicoll JA, Ironside JW, Love S, Alberts MJ, Bone I. Cerebral amyloid angiopathy-related hemorrhage. Interaction of APOE epsilon2 with putative clinical risk factors. Stroke. 1999;30:1643-6

58. Jarvik GP, Wijsman EM, Kukull WA, Schellenberg GD, Yu C, Larson EB. Interactions of apolipoprotein E genotype, total cholesterol level, age, and sex in prediction of Alzheimer's disease: a case-control study. Neurology. 1995;45:1092-6.

59. Burns M, Duff K. Use of in vivo models to study the role of cholesterol in the etiology of Alzheimer's disease. Neurochem Res. 2003;28:979-86.

60. Kim J, Basak JM, Holtzman DM. The role of apolipoprotein E in Alzheimer's disease. Neuron. 2009;63:287-303.

61. Breteler MM. Vascular involvement in cognitive decline and dementia. Epidemiologic evidence from the Rotterdam Study and the Rotterdam Scan Study. Ann NY Acad Sci. 2000;903: 457-65

62. Kivipelto M, Helkala EL, Laakso MP, et al. Midlife vascular risk factors and Alzheimer's disease in later life: longitudinal, population based study. BMJ. 2001;322:1447-51

63. Pappolla MA, Bryant-Thomas TK, Herbert D, et al. Mild hypercholesterolemia is an early risk factor for the development of Alzheimer amyloid pathology. Neurology. 2003;61:199-205.

64. Simons M, Keller P, De Strooper B, Beyreuther K, Dotti CG, Simons K. Cholesterol depletion inhibits the generation of betaamyloid in hippocampal neurons. Proc Natl Acad Sci USA. 1998;95:6460-4

65. Refolo LM, Malester B, LaFrancois J, et al. Hypercholesterolemia accelerates the Alzheimer's amyloid pathology in a transgenic mouse model. Neurobiol Dis. 2000;7:321-31.

66. Li L, Cao D, Garber DW, Kim H, Fukuchi K. Association of aortic atherosclerosis with cerebral beta-amyloidosis and learning deficits in a mouse model of Alzheimer's disease. Am J Pathol. 2003; $163: 2155-64$
67. Hirsch-Reinshagen V, Maia LF, Burgess BL, et al. The absence of ABCA1 decreases soluble ApoE levels but does not diminish amyloid deposition in two murine models of Alzheimer disease. J Biol Chem. 2005;280:43243-56.

68. Rockwood K, Kirkland S, Hogan DB, et al. Use of lipid-lowering agents, indication bias, and the risk of dementia in communitydwelling elderly people. Arch Neurol. 2002;59:223-7.

69. Yaffe K, Barrett-Connor E, Lin F, Grady D. Serum lipoprotein levels, statin use, and cognitive function in older women. Arch Neurol. 2002;59:378-84.

70. Wolozin B, Wang SW, Li NC, Lee A, Lee TA, Kazis LE. Simvastatin is associated with a reduced incidence of dementia and Parkinson's disease. BMC Med. 2007;5:20.

71. Fassbender K, Simons M, Bergmann C, et al. Simvastatin strongly reduces levels of Alzheimer's disease beta -amyloid peptides Abeta 42 and Abeta 40 in vitro and in vivo. Proc Natl Acad Sci USA. 2001;98:5856-61

72. Paris D, Townsend KP, Obregon DF, Humphrey J, Mullan M, Yokota K. Pro-inflammatory effect of freshly solubilized betaamyloid peptides in the brain. Prostaglandins Other Lipid Mediat. 2002;70:1-12.

73. Wolozin B, Manger J, Bryant R, Cordy J, Green RC, McKee A. Reassessing the relationship between cholesterol, statins and Alzheimer's disease. Acta Neurol Scand Suppl. 2006;185:63-70.

74. Solomon A, Sippola R, Soininen H, et al. Lipid-lowering treatment is related to decreased risk of dementia: a population-based study (FINRISK). Neurodegener Dis. 2010;7:180-2.

75. Sparks DL, Connor DJ, Sabbagh MN, Petersen RB, Lopez J, Browne P. Circulating cholesterol levels, apolipoprotein E genotype and dementia severity influence the benefit of atorvastatin treatment in Alzheimer's disease: results of the Alzheimer's Disease Cholesterol-Lowering Treatment (ADCLT) trial. Acta Neurol Scand Suppl. 2006;185:3-7.

76. Feldman HH, Doody RS, Kivipelto $M$, et al. Randomized controlled trial of atorvastatin in mild to moderate Alzheimer disease: LEADe. Neurology. 2010;74:956-64.

77. Sano M. Multi-center, randomized, double-blind, placebocontrolled trial of simvastatin to slow the progression of Alzheimer's disease. Alzheimers Dement. 2008;4(Suppl 4): T200.

78. Amarenco P, Bogousslavsky J, Callahan A, 3rd, et al. High-dose atorvastatin after stroke or transient ischemic attack. N Engl J Med. 2006;355:549-59.

79. Shobab LA, Hsiung GY, Feldman HH. Cholesterol in Alzheimer's disease. Lancet Neurol. 2005;4:841-52.

80. Elias MF, Wolf PA, D'Agostino RB, Cobb J, White LR. Untreated blood pressure level is inversely related to cognitive functioning: the Framingham Study. Am J Epidemiol. 1993;138:353-64.

81. Launer LJ, Masaki K, Petrovitch H, Foley D, Havlik RJ. The association between midlife blood pressure levels and late-life cognitive function. The Honolulu-Asia Aging Study. JAMA. 1995:274:1846-51

82. Sparks DL, Scheff SW, Liu H, Landers TM, Coyne CM, Hunsaker JC, 3rd. Increased incidence of neurofibrillary tangles (NFT) in non-demented individuals with hypertension. J Neurol Sci. $1995 ; 131: 162-9$

83. Skoog I. Status of risk factors for vascular dementia. Neuroepidemiology. 1998;17:2-9.

84. Launer LJ, Ross GW, Petrovitch H, et al. Midlife blood pressure and dementia: the Honolulu-Asia aging study. Neurobiol Aging. 2000;21:49-55

85. Petrovitch $\mathrm{H}$, White LR, Izmirilian $\mathrm{G}$, et al. Midlife blood pressure and neuritic plaques, neurofibrillary tangles, and brain weight at death: the HAAS. Honolulu-Asia aging Study. Neurobiol Aging. 2000;21:57-62.

86. Forette F, Seux ML, Staessen JA, et al. Prevention of dementia in randomised double-blind placebo-controlled Systolic Hypertension in Europe (Syst-Eur) trial. Lancet. 1998;352: 1347-51.

87. Ohrui T, Tomita N, Sato-Nakagawa T, et al. Effects of brainpenetrating ACE inhibitors on Alzheimer disease progression. Neurology. 2004;63:1324-5. 
88. Birkenhager WH, Forette F, Staessen JA. Dementia and antihypertensive treatment. Curr Opin Nephrol Hypertens. 2004; $13: 225-30$.

89. Hemming ML, Selkoe DJ. Amyloid beta-protein is degraded by cellular angiotensin-converting enzyme (ACE) and elevated by an ACE inhibitor. J Biol Chem. 2005;280:37644-50.

90. Kilander L, Nyman H, Boberg M, Hansson L, Lithell H. Hypertension is related to cognitive impairment: a 20-year follow-up of 999 men. Hypertension. 1998;31:780-6.

91. Li NC, Lee A, Whitmer RA, et al. Use of angiotensin receptor blockers and risk of dementia in a predominantly male population: prospective cohort analysis. BMJ. 2010;340:b5465.

92. Fournier A, Oprisiu-Fournier R, Serot JM, et al. Prevention of dementia by antihypertensive drugs: how AT1-receptor-blockers and dihydropyridines better prevent dementia in hypertensive patients than thiazides and ACE-inhibitors. Expert Rev Neurother. 2009;9:1413-31.

93. Oprisiu-Fournier R, Serot JM, Achard JM, Messerli FH, Black SE, Fournier A. AT1 receptor blockers for cognition decline after cardiac surgery? Stroke. 2006;37:2666.

94. Leibson CL, Rocca WA, Hanson VA, et al. Risk of dementia among persons with diabetes mellitus: a population-based cohort study. Am J Epidemiol. 1997; 145:301-8.

95. Yoshitake T, Kiyohara Y, Kato I, et al. Incidence and risk factors of vascular dementia and Alzheimer's disease in a defined elderly Japanese population: the Hisayama Study. Neurology. 1995;45: 1161-8.

96. Whitmer RA, Sidney S, Selby J, Johnston SC, Yaffe K. Midlife cardiovascular risk factors and risk of dementia in late life. Neurology. 2005;64:277-81.

97. Ott A, Stolk RP, van Harskamp F, Pols HA, Hofman A, Breteler MM. Diabetes mellitus and the risk of dementia: The Rotterdam Study. Neurology. 1999;53:1937-42.

98. Xu WL, von Strauss E, Qiu CX, Winblad B, Fratiglioni L. Uncontrolled diabetes increases the risk of Alzheimer's disease: a population-based cohort study. Diabetologia. 2009;52:1031-9.

99. Craft S. Insulin resistance syndrome and Alzheimer's disease: ageand obesity-related effects on memory, amyloid, and inflammation. Neurobiol Aging. 2005;26:65-9.

100. Watson GS, Peskind ER, Asthana S, et al. Insulin increases CSF Abeta42 levels in normal older adults. Neurology. 2003;60: 1899-903.

101. Gasparini L, Gouras GK, Wang R, et al. Stimulation of betaamyloid precursor protein trafficking by insulin reduces intraneuronal beta-amyloid and requires mitogen-activated protein kinase signaling. J Neurosci. 2001;21:2561-70.

102. Fishel MA, Watson GS, Montine TJ, et al. Hyperinsulinemia provokes synchronous increases in central inflammation and beta-amyloid in normal adults. Arch Neurol. 2005;62:1539-44.

103. Gustafson D, Rothenberg E, Blennow K, Steen B, Skoog I. An 18year follow-up of overweight and risk of Alzheimer disease. Arch Intern Med. 2003;163:1524-8.

104. Hayden KM, Zandi PP, Lyketsos CG, et al. Vascular risk factors for incident Alzheimer disease and vascular dementia: the Cache County study. Alzheimer Dis Assoc Disord. 2006;20:93-100.

105.Expert Panel on Detection E, and Treatment of High Blood Cholesterol in Adults. Executive Summary of The Third Report of The National Cholesterol Education Program (NCEP) Expert Panel on Detection, Evaluation, And Treatment of High Blood Cholesterol In Adults (Adult Treatment Panel III). JAMA. 2001; 285:2486-97.

106. Alexander CM, Landsman PB, Teutsch SM, Haffner SM. NCEPdefined metabolic syndrome, diabetes, and prevalence of coronary heart disease among NHANES III participants age 50 years and older. Diabetes. 2003;52:1210-14.

107. Razay G, Vreugdenhil A, Wilcock G. The metabolic syndrome and Alzheimer disease. Arch Neurol. 2007;64:93-6.

108. Bostom AG, Silbershatz H, Rosenberg IH, et al. Nonfasting plasma total homocysteine levels and all-cause and cardiovascular disease mortality in elderly Framingham men and women. Arch Intern Med. 1999;159:1077-80.
109. Garcia A. Cobalamin and homocysteine in older adults: do we need to test for serum levels in the work-up of dementia? Alzheimers Dement. 2007;3:318-24.

110. Bostom AG, Rosenberg IH, Silbershatz H, et al. Nonfasting plasma total homocysteine levels and stroke incidence in elderly persons: the Framingham Study. Ann Intern Med. 1999;131: $352-5$.

111. Seshadri S, Beiser A, Selhub J, et al. Plasma homocysteine as a risk factor for dementia and Alzheimer's disease. N Engl J Med. 2002;346:476-83.

112. Clarke R, Smith AD, Jobst KA, Refsum H, Sutton L, Ueland PM. Folate, vitamin B12, and serum total homocysteine levels in confirmed Alzheimer disease. Arch Neurol. 1998;55:1449-55.

113. Garcia A, Haron Y, Pulman K, Hua L, Freedman M. Increases in homocysteine are related to worsening of stroop scores in healthy elderly persons: a prospective follow-up study. J Gerontol A Biol Sci Med Sci. 2004;59:1323-7.

114. Garcia A, Zanibbi K. Homocysteine and cognitive function in elderly people. CMAJ. 2004;171:897-904.

115. Lee PN. Smoking and Alzheimer's disease: a review of the epidemiological evidence. Neuroepidemiology. 1994;13:131-44.

116. Aggarwal NT, Bienias JL, Bennett DA, et al. The relation of cigarette smoking to incident Alzheimer's disease in a biracial urban community population. Neuroepidemiology. 2006;26: $140-6$.

117. Sacco KA, Bannon KL, George TP. Nicotinic receptor mechanisms and cognition in normal states and neuropsychiatric disorders. J Psychopharmacol. 2004; 18:457-74.

118. Hellstrom-Lindahl E, Mousavi M, Ravid R, Nordberg A. Reduced levels of Abeta 40 and Abeta 42 in brains of smoking controls and Alzheimer's patients. Neurobiol Dis. 2004;15:351-60.

119. Verhoeff NP. Acetylcholinergic neurotransmission and the betaamyloid cascade: implications for Alzheimer's disease. Expert Rev Neurother. 2005;5:277-84.

120. Black SE, Patterson C, Feightner J. Preventing dementia. Can J Neurol Sci. 2001;28 Suppl 1:S56-66.

121.Patterson C, Feightner J, Garcia A, MacKnight C. General risk factors for dementia: a systematic evidence review. Alzheimers Dement. 2007;3:341-7.

122.Patterson C, Feightner JW, Garcia A, Hsiung GY, MacKnight C, Sadovnick AD. Diagnosis and treatment of dementia: 1. Risk assessment and primary prevention of Alzheimer disease. CMAJ. 2008; 178:548-56.

123. Roher AE, Esh C, Kokjohn TA, et al. Circle of Willis atherosclerosis is a risk factor for sporadic Alzheimer's disease. Arterioscler Thromb Vasc Biol. 2003;23:2055-62.

124. Roher AE, Esh C, Rahman A, Kokjohn TA, Beach TG. Atherosclerosis of cerebral arteries in Alzheimer disease. Stroke. 2004;35:2623-7.

125. Honig LS, Kukull W, Mayeux R. Atherosclerosis and AD: analysis of data from the US National Alzheimer's Coordinating Center. Neurology. 2005;64:494-500.

126. Hofman A, Ott A, Breteler MM, et al. Atherosclerosis, apolipoprotein E, and prevalence of dementia and Alzheimer's disease in the Rotterdam Study. Lancet. 1997;349:151-4.

127. Belohlavek M, Jiamsripong P, Calleja AM, et al. Patients with Alzheimer disease have altered transmitral flow: echocardiographic analysis of the vortex formation time. J Ultrasound Med. 2009;28:1493-500.

128. Pettersen JA, Gao FQ, Black SE. Carotid artery bifurcation tortuosity as a possible contributor to substantia innominata atrophy and executive dysfunction in Alzheimer disease. Stroke. 2008;39:682-3

129. Holland CM, Smith EE, Csapo I, et al. Spatial distribution of whitematter hyperintensities in Alzheimer disease, cerebral amyloid angiopathy, and healthy aging. Stroke. 2008;39:1127-33.

130. Roher AE, Kuo YM, Esh C, et al. Cortical and leptomeningeal cerebrovascular amyloid and white matter pathology in Alzheimer's disease. Mol Med 2003;9:112-22.

131. Black S, Gao F, Bilbao J. Understanding white matter disease: imaging-pathological correlations in vascular cognitive impairment. Stroke. 2009;40:S48-52. 
132. Moody DM, Brown WR, Challa VR, Anderson RL. Periventricular venous collagenosis: association with leukoaraiosis. Radiology. 1995;194:469-76.

133. Heyman A, Fillenbaum GG, Welsh-Bohmer KA, et al. Cerebral infarcts in patients with autopsy-proven Alzheimer's disease: CERAD, part XVIII. Consortium to Establish a Registry for Alzheimer's Disease. Neurology. 1998;51:159-62.

134.Zekry D, Duyckaerts C, Belmin J, Geoffre C, Moulias R, Hauw JJ. Cerebral amyloid angiopathy in the elderly: vessel walls changes and relationship with dementia. Acta Neuropathol (Berl). 2003; 106:367-73.

135. Koistinaho M, Koistinaho J. Interactions between Alzheimer's disease and cerebral ischemia--focus on inflammation. Brain Res Brain Res Rev. 2005;48:240-50.

136. Whitehead SN, Hachinski VC, Cechetto DF. Interaction between a rat model of cerebral ischemia and beta-amyloid toxicity: inflammatory responses. Stroke. 2005;36:107-12.

137.Pluta R, Barcikowska M, Misicka A, Lipkowski AW, Spisacka S, Januszewski S. Ischemic rats as a model in the study of the neurobiological role of human beta-amyloid peptide. Timedependent disappearing diffuse amyloid plaques in brain. Neuroreport. 1999;10:3615-19.

138. Pratico D. Peripheral biomarkers of oxidative damage in Alzheimer's disease: the road ahead. Neurobiol Aging. 2005;26: 581-3.

139. Crack PJ, Taylor JM. Reactive oxygen species and the modulation of stroke. Free Radic Biol Med. 2005;38:1433-44.

140. Migliore L, Fontana I, Trippi F, et al. Oxidative DNA damage in peripheral leukocytes of mild cognitive impairment and $\mathrm{AD}$ patients. Neurobiol Aging. 2005;26:567-73.

141. Iadecola C, Zhang F, Niwa K, et al. SOD1 rescues cerebral endothelial dysfunction in mice overexpressing amyloid precursor protein. Nat Neurosci. 1999;2:157-61.

142. Banati RB, Gehrmann J, Wiessner C, Hossmann KA, Kreutzberg GW. Glial expression of the beta-amyloid precursor protein (APP) in global ischemia. J Cereb Blood Flow Metab. 1995;15: 647-54.

143. Yokota M, Saido TC, Tani E, Yamaura I, Minami N. Cytotoxic fragment of amyloid precursor protein accumulates in hippocampus after global forebrain ischemia. J Cereb Blood Flow Metab. 1996;16:1219-23.

144.DeKosky ST, Ikonomovic MD, Wang X, et al. Plasma and cerebrospinal fluid alpha1-antichymotrypsin levels in Alzheimer's disease: correlation with cognitive impairment. Ann Neurol. 2003;53:81-90.

145. Townsend KP, Pratico D. Novel therapeutic opportunities for Alzheimer's disease: focus on nonsteroidal anti-inflammatory drugs. Faseb J. 2005;19:1592-601.

146. Arvanitakis Z, Grodstein F, Bienias JL, et al. Relation of NSAIDs to incident $\mathrm{AD}$, change in cognitive function, and $\mathrm{AD}$ pathology. Neurology. 2008;70:2219-25.

147. Breitner JC, Haneuse SJ, Walker R, et al. Risk of dementia and AD with prior exposure to NSAIDs in an elderly community-based cohort. Neurology. 2009;72:1899-905.

148. Sonnen JA, Larson EB, Walker RL, et al. Nonsteroidal antiinflammatory drugs are associated with increased neuritic plaques. Neurology. 2010;75:1203-10.

149. Bateman RJ, Munsell LY, Morris JC, Swarm R, Yarasheski KE, Holtzman DM. Human amyloid-beta synthesis and clearance rates as measured in cerebrospinal fluid in vivo. Nat Med. 2006; 12:856-61.

150. Claassen JA, Jansen RW. Cholinergically mediated augmentation of cerebral perfusion in Alzheimer's disease and related cognitive disorders: the cholinergic-vascular hypothesis. J Gerontol A Biol Sci Med Sci. 2006;61:267-71.

151. Aucoin JS, Jiang P, Aznavour N, et al. Selective cholinergic denervation, independent from oxidative stress, in a mouse model of Alzheimer's disease. Neuroscience. 2005;132:73-86.

152. Minoshima S, Giordani B, Berent S, Frey KA, Foster NL, Kuhl DE. Metabolic reduction in the posterior cingulate cortex in very early Alzheimer's disease. Ann Neurol. 1997;42:85-94

153. Nagata K, Sato M, Satoh Y, et al. Hemodynamic aspects of Alzheimer's disease. Ann N Y Acad Sci. 2002:977:391-402.
154. Serpell LC. Alzheimer's amyloid fibrils: structure and assembly. Biochim Biophys Acta. 2000;1502:16-30.

155. Qi-Takahara Y, Morishima-Kawashima M, Tanimura Y, et al. Longer forms of amyloid beta protein: implications for the mechanism of intramembrane cleavage by gamma-secretase. J Neurosci. 2005;25:436-45.

156. Hardy J. Amyloid, the presenilins and Alzheimer's disease. Trends Neurosci. 1997;20:154-9.

157. Hyman BT, West HL, Rebeck GW, Lai F, Mann DM. Neuropathological changes in Down's syndrome hippocampal formation. Effect of age and apolipoprotein E genotype. Arch Neurol. 1995;52:373-8.

158. De Strooper B, Saftig P, Craessaerts K, et al. Deficiency of presenilin-1 inhibits the normal cleavage of amyloid precursor protein. Nature. 1998;391:387-90.

159.Lue LF, Kuo YM, Roher AE, et al. Soluble amyloid beta peptide concentration as a predictor of synaptic change in Alzheimer's disease. Am J Pathol. 1999;155:853-62.

160. Berg L, McKeel DW, Jr., Miller JP, et al. Clinicopathologic studies in cognitively healthy aging and Alzheimer's disease: relation of histologic markers to dementia severity, age, sex, and apolipoprotein E genotype. Arch Neurol. 1998;55:326-35

161.Klein WL, Stine WB, Jr., Teplow DB. Small assemblies of unmodified amyloid beta-protein are the proximate neurotoxin in Alzheimer's disease. Neurobiol Aging. 2004;25:569-80.

162. Walsh DM, Lomakin A, Benedek GB, Condron MM, Teplow DB. Amyloid beta-protein fibrillogenesis. Detection of a protofibrillar intermediate. J Biol Chem. 1997;272:22364-72.

163. Bitan G, Kirkitadze MD, Lomakin A, Vollers SS, Benedek GB, Teplow DB. Amyloid beta -protein (Abeta) assembly: Abeta 40 and Abeta 42 oligomerize through distinct pathways. Proc Natl Acad Sci USA. 2003;100:330-5.

164.Gorman PM, Yip CM, Fraser PE, Chakrabartty A. Alternate aggregation pathways of the Alzheimer beta-amyloid peptide: Abeta association kinetics at endosomal pH. J Mol Biol. 2003; 325:743-57.

165. Huang TH, Yang DS, Fraser PE, Chakrabartty A. Alternate aggregation pathways of the Alzheimer beta-amyloid peptide. An in vitro model of preamyloid. J Biol Chem. 2000;275: 36436-40

166.Petersen RC, Parisi JE, Dickson DW, et al. Neuropathologic features of amnestic mild cognitive impairment. Arch Neurol. 2006;63:665-72

167. Hartley DM, Walsh DM, Ye CP, et al. Protofibrillar intermediates of amyloid beta-protein induce acute electrophysiological changes and progressive neurotoxicity in cortical neurons. J Neurosci. 1999;19:8876-84.

168. Cleary JP, Walsh DM, Hofmeister JJ, et al. Natural oligomers of the amyloid-beta protein specifically disrupt cognitive function. Nat Neurosci. 2005;8:79-84

169. Morimoto A, Irie K, Murakami K, et al. Aggregation and neurotoxicity of mutant amyloid beta (A beta) peptides with proline replacement: importance of turn formation at positions 22 and 23. Biochem Biophys Res Commun. 2002;295:306-11.

170. Weller RO, Boche D, Nicoll JA. Microvasculature changes and cerebral amyloid angiopathy in Alzheimer's disease and their potential impact on therapy. Acta Neuropathol. 2009;118: 87-102.

171. Herzig MC, Winkler DT, Burgermeister P, et al. Abeta is targeted to the vasculature in a mouse model of hereditary cerebral hemorrhage with amyloidosis. Nat Neurosci. 2004;7:954-60.

172. Fryer JD, Simmons K, Parsadanian M, et al. Human apolipoprotein E4 alters the amyloid-beta 40:42 ratio and promotes the formation of cerebral amyloid angiopathy in an amyloid precursor protein transgenic model. J Neurosci. 2005;25: 2803-10.

173. Thal DR, Griffin WS, de Vos RA, Ghebremedhin E. Cerebral amyloid angiopathy and its relationship to Alzheimer's disease. Acta Neuropathol. 2008;115:599-609.

174. Pettersen JA, Sathiyamoorthy G, Gao FQ, et al. Microbleed topography, leukoaraiosis, and cognition in probable Alzheimer disease from the Sunnybrook dementia study. Arch Neurol. $2008 ; 65: 790-5$ 
175. Johnson KA, Gregas M, Becker JA, et al. Imaging of amyloid burden and distribution in cerebral amyloid angiopathy. Ann Neurol. 2007;62:229-34.

176. Greenberg SM, Vernooij MW, Cordonnier C, et al. Cerebral microbleeds: a guide to detection and interpretation. Lancet Neurol. 2009;8:165-74.

177. Kalaria RN. The blood-brain barrier and cerebrovascular pathology in Alzheimer's disease. Ann N Y Acad Sci. 1999;893:113-25.

178. Nalivaevaa NN, Fisk L, Kochkina EG, et al. Effect of hypoxia/ischemia and hypoxic preconditioning/reperfusion on expression of some amyloid-degrading enzymes. Ann NY Acad Sci. 2004;1035:21-33

179. Smith EE, Greenberg SM. Beta-amyloid, blood vessels, and brain function. Stroke. 2009;40:2601-6.

180. Nicoll JA, Yamada M, Frackowiak J, Mazur-Kolecka B, Weller RO. Cerebral amyloid angiopathy plays a direct role in the pathogenesis of Alzheimer's disease. Pro-CAA position statement. Neurobiol Aging. 2004;25:589-97.

181. Attems J, Jellinger KA. Only cerebral capillary amyloid angiopathy correlates with Alzheimer pathology--a pilot study. Acta Neuropathol (Berl). 2004; 107:83-90

182. Christie R, Yamada M, Moskowitz M, Hyman B. Structural and functional disruption of vascular smooth muscle cells in a transgenic mouse model of amyloid angiopathy. Am J Pathol. 2001;158:1065-71

183. Chen K, Ayutyanont N, Langbaum JB, et al. Characterizing Alzheimer's disease using a hypometabolic convergence index. Neuroimage. 2011;56:52-60.

184.Jagust W, Reed B, Mungas D, Ellis W, Decarli C. What does fluorodeoxyglucose PET imaging add to a clinical diagnosis of dementia? Neurology. 2007;69:871-7.

185. Agdeppa ED, Kepe V, Liu J, et al. 2-Dialkylamino-6acylmalononitrile substituted naphthalenes (DDNP analogs): novel diagnostic and therapeutic tools in Alzheimer's disease. Mol Imaging Biol. 2003;5:404-17.

186. Verhoeff NPLG. Amyloid imaging in vivo: implications for Alzheimer's disease management. Expert Opinion on Medical Diagnostics. 2007;1:337-49.

187. Vandenberghe R, Van Laere K, Ivanoiu A, et al. ${ }^{18} \mathrm{~F}$-flutemetamol amyloid imaging in Alzheimer disease and mild cognitive impairment: a phase 2 trial. Ann Neurol. 2010;68:319-29.

188. Barthel H, Gertz HJ, Dresel S, et al. Cerebral amyloid-beta PET with florbetaben $\left({ }^{18} \mathrm{~F}\right)$ in patients with Alzheimer's disease and healthy controls: a multicentre phase 2 diagnostic study. Lancet Neurol. 2011;10:424-35.

189. Clark CM, Schneider JA, Bedell BJ, et al. Use of florbetapir-PET for imaging beta-amyloid pathology. JAMA. 2011;305:275-83 .

190. Choi SR, Schneider JA, Bennett DA, et al. Correlation of amyloid PET ligand florbetapir F 18 binding with Abeta aggregation and neuritic plaque deposition in postmortem brain tissue. Alzheimer Dis Assoc Disord. 2012;26:8-16.

191.FDA Approves ${ }^{18}$ F-Florbetapir PET Agent. J Nucl Med. 2012; $53: 15 \mathrm{~N}$.

192. Wengenack TM, Jack CR, Jr., Garwood M, Poduslo JF. MR microimaging of amyloid plaques in Alzheimer's disease transgenic mice. Eur J Nucl Med Mol Imaging. 2008;35 Suppl $1:$ S82-8.

193. Nakada T, Matsuzawa H, Igarashi H, Fujii Y, Kwee IL. In vivo visualization of senile-plaque-like pathology in Alzheimer's disease patients by MR microscopy on a $7 \mathrm{~T}$ system. J Neuroimaging. 2008;18:125-9.

194. Braak H, Braak E. Neuropathological stageing of Alzheimer-related changes. Acta Neuropathol (Berl). 1991;82:239-59.

195. Thal DR, Rub U, Schultz C, et al. Sequence of Abeta-protein deposition in the human medial temporal lobe. J Neuropathol Exp Neurol. 2000;59:733-48.

196. Thal DR, Rub U, Orantes M, Braak H. Phases of A beta-deposition in the human brain and its relevance for the development of $\mathrm{AD}$. Neurology. 2002;58:1791-800.

197. McGowan E, Sanders S, Iwatsubo T, et al. Amyloid phenotype characterization of transgenic mice overexpressing both mutant amyloid precursor protein and mutant presenilin 1 transgenes. Neurobiol Dis. 1999;6:231-44.
198.Price JC, Klunk WE, Lopresti BJ, et al. Kinetic modeling of amyloid binding in humans using PET imaging and Pittsburgh Compound-B. J Cereb Blood Flow Metab. 2005;25:1528-47.

199. Jack CR, Jr., Lowe VJ, Weigand SD, et al. Serial PIB and MRI in normal, mild cognitive impairment and Alzheimer's disease: implications for sequence of pathological events in Alzheimer's disease. Brain. 2009:132:1355-65.

200.Jack CR, Jr., Wiste HJ, Vemuri P, et al. Brain beta-amyloid measures and magnetic resonance imaging atrophy both predict time-to-progression from mild cognitive impairment to Alzheimer's disease. Brain. 2010;133:3336-48.

201. Rowe CC, Villemagne VL. Brain amyloid imaging. J Nucl Med. 2011;52:1733-40.

202. Villain N, Chetelat G, Grassiot B, et al. Regional dynamics of amyloid-beta deposition in healthy elderly, mild cognitive impairment and Alzheimer's disease: a voxelwise PiB-PET longitudinal study. Brain. 2012 (Epub ahead of print).

203. Rinne JO, Brooks DJ, Rossor MN, et al. 11C-PiB PET assessment of change in fibrillar amyloid-beta load in patients with Alzheimer's disease treated with bapineuzumab: a phase 2, double-blind, placebo-controlled, ascending-dose study. Lancet Neurol. 2010;9:363-72.

204. Viswanathan A, Chabriat H. Cerebral microhemorrhage. Stroke. 2006;37:550-5

205. Vardy ER, Hussain I, Hooper NM. Emerging therapeutics for Alzheimer's disease. Expert Rev Neurother. 2006;6:695-704.

206. Townsend M. When will Alzheimer's Disease be cured? A pharmaceutical perspective. J Alzheimers Dis. 2011;24:43-52.

207. Wilcock GK, Black SE, Hendrix SB, Zavitz KH, Swabb EA, Laughlin MA. Efficacy and safety of tarenflurbil in mild to moderate Alzheimer's disease: a randomised phase II trial. Lancet Neurol. 2008;7:483-93.

208. Green RC, Schneider LS, Amato DA, et al. Effect of tarenflurbil on cognitive decline and activities of daily living in patients with mild Alzheimer disease: a randomized controlled trial. JAMA. 2009;302:2557-64

209. Geerts H. NC-531 (Neurochem). Curr Opin Investig Drugs. 2004;5: 95-100.

210. McLaurin J, Kierstead ME, Brown ME, et al. Cyclohexanehexol inhibitors of Abeta aggregation prevent and reverse Alzheimer phenotype in a mouse model. Nat Med. 2006;12:801-8.

211. Janus C, Pearson J, McLaurin J, et al. A beta peptide immunization reduces behavioural impairment and plaques in a model of Alzheimer's disease. Nature. 2000;408:979-82

212. Schenk D, Barbour R, Dunn W, et al. Immunization with amyloidbeta attenuates Alzheimer-disease-like pathology in the PDAPP mouse. Nature. 1999;400:173-7.

213.Pfeifer M, Boncristiano S, Bondolfi L, et al. Cerebral hemorrhage after passive anti-Abeta immunotherapy. Science. 2002;298: 1379.

214. Nicoll JA, Wilkinson D, Holmes C, Steart P, Markham H, Weller RO. Neuropathology of human Alzheimer disease after immunization with amyloid-beta peptide: a case report. Nat Med. 2003;9:448-52.

215. Orgogozo JM, Gilman S, Dartigues JF, et al. Subacute meningoencephalitis in a subset of patients with AD after Abeta42 immunization. Neurology. 2003;61:46-54.

216. Holmes C, Boche D, Wilkinson D, et al. Long-term effects of Abeta42 immunisation in Alzheimer's disease: follow-up of a randomised, placebo-controlled phase I trial. Lancet. 2008;372: 216-23.

217. Delrieu J, Ousset PJ, Caillaud C, Vellas B. 'Clinical trials in Alzheimer's disease': immunotherapy approaches. J Neurochem. 2012;120 Suppl 1:186-93.

218. Sperling RA, Aisen PS, Beckett LA, et al. Toward defining the preclinical stages of Alzheimer's disease: recommendations from the National Institute on Aging-Alzheimer's Association workgroups on diagnostic guidelines for Alzheimer's disease. Alzheimers Dement. 2011;7:280-92. 